\title{
EXCESSIVE NOISE PARADOXES IN URBAN TRANSPORTATION NETWORKS
}

\author{
YI WANG ${ }^{\mathrm{a}}$ and W. Y. SZETO ${ }^{\mathrm{b}}$ \\ ${ }^{a}$ Department of Civil Engineering, The University of Hong Kong, China \\ Email: zoewang@hku.hk \\ ${ }^{b}$ Department of Civil Engineering, The University of Hong Kong, China \\ The University of Hong Kong Shenzhen Institute of Research and Innovation, China \\ Email: ceszeto@hku.hk
}

\begin{abstract}
Braess' paradox demonstrates that adding a new link to a traffic network may actually reduce the network's overall efficiency in terms of total system travel time. This phenomenon has been researched thoroughly, but total system travel time is not the only measure that can be used to evaluate the performance of a network. An analogue of the Braess paradox related to traffic noise is less well known, but is also worth exploring. For traffic assignments in situations of non-cooperative behavior, some network improvements or traffic control strategies can cause the total amount of excessive noise (and its cost) to increase. This study demonstrates the existence of such an excessive noise paradox using examples drawn from several small networks. The simultaneous and asynchronous occurrences among the excessive noise paradox, the emission paradox and the Braess paradox are also examined. The study finds that the excessive noise paradox can be triggered by network control strategies such as demand change, link addition or speed limit implementation. These findings indicate the inadequacy of designing road networks solely to mitigate congestion, as such designs may cause increased emissions or excessive noise.
\end{abstract}

Keywords: Braess' paradox, Emission paradox, Excessive noise paradox, Speed limit

\section{INTRODUCTION}

Braess (1968) pointed out the counterintuitive phenomenon whereby the expansion of a road network may cause longer individual running times. This problem, known as the Braess paradox of traffic flow, has received a great deal of attention. Such paradoxical phenomena are not only theoretically interesting, but are also of vital practical significance. Infrastructure project investments are very expensive, but budgets are limited, so designers should be very cautious about improving rather than aggravating transportation systems.

In addition to Braess' paradox, other paradoxes associated with transportation networks have been discussed in the literature. The following are some examples.

- Pigou (1920), Knight (1924) and Downs (1962) illustrated the Pigou-Knight-Downs Paradox-an increase in road capacity may not decrease total travel time, because the improvement may attract travel demand on the road.

- $\quad$ Downs (1962) and Thomson (1977) introduced the Downs-Thomson Paradox-an increase in the road capacity of a network that has both road traffic and transit may increase the total travel time, because more users may be attracted to travel on the road, and waiting times for transit services may be higher after the improvement.

- Smith (1978) showed that, counterintuitively, a reduction in total journey time may be achieved by increasing the travel time along a particular uncongested link.

- $\quad$ Fisk (1979) constructed a single-mode Wardrop equilibrium problem to demonstrate that an increase in input flows may lead to decreased costs of both origin-destination (O-D) travel and total travel. Fisk also showed that in an equilibrium assignment problem with auto and transit modes, an increase in auto input flows may lead to a decrease in transit O-D costs.

- Dafermos and Nagurney (1984) showed that an increase in the travel demand for a particular 
O-D pair can result in a decrease in the travelers' costs between other O-D pairs.

- $\quad$ Sheffi and Daganzo (1978) introduced a counterintuitive phenomenon similar to Braess' paradox. This phenomenon arises in the context of stochastic network loading models: the total travel time in the system may increase with an addition of a link to the network. Sheffi also discussed the stochastic assignment paradox in which the total travel cost increases when an inferior travel alternative is marginally improved.

- $\quad$ Steinberg and Stone (1988) presented a new paradox that contrasts with Braess' paradox. This new paradox indicates that in a congested transportation network, a sufficiently high increase in the congestion effect along a route can result in the abandonment of a different route having the same origin and destination, while the original route continues to be used.

- $\quad$ Cohen and Kelly (1990) provided an example of a simple queuing network in which added capacity leads to an increase in the mean transit time for every network user.

- Arnott et al. (1993) showed that a paradox may result when travel modes, origins, destinations and routes are fixed, but the users are free to choose when to travel. Specifically, a capacity expansion can increase travel costs (which consist of the sum of travel time and schedule delay costs). For a corridor with two groups of drivers, Arnott et al. showed that expanding the capacity of an upstream bottleneck raises travel costs when the reduction in congestion upstream is more than offset by increased congestion downstream.

- Daganzo (1996) depicted an interesting capacity paradox example: in a queuing network with equilibrium traffic flow, the expansion of the capacity of a bottleneck may reduce the total maximum throughput of the network due to the spillover effect of vehicular queues.

- $\quad$ Yang and Bell (1998) demonstrated another capacity paradox whereby creating a new link in a road network may actually reduce network capacity.

- Akamatsu (2000) identified a capacity-increasing paradox with dynamic flows on two symmetrical networks: an "evening-rush-hour" network with a one-to-many O-D pattern and a "morning-rush-hour" network with a many-to-one O-D pattern. This problem was a dynamic version of Braess' paradox. Using a point queue assumption, Akamatsu showed that improving the capacity of a certain link on a network worsens the total travel cost over the network. He found that the conditions for the occurrence of this paradox in the two model networks were different.

- Z Zhang et al. (2008) discovered some new dynamic phenomena related to Braess' paradox in a transportation network, where both the departure times and route choices are considered simultaneously. These new Braess' paradoxes with dynamic user response were identified with respect to both the point queue and physical queue assumptions. Zhang et al. presented a numerical example in which a paradox may occur in a network when a physical queue assumption is made, but that paradox may not be found in the network if the point queue assumption is adopted.

- $\quad$ Lin and Lo (2009) analyzed a dynamic extension of Braess' paradox by using the original five-link Braess paradox network and a point queue assumption. They found that the "surprising result" reported in previous studies with link performance functions (that a system can spontaneously grow out of Braess' paradox if the demand is sufficiently high), does not occur with time-dependent queues.

- $\quad$ Szeto et al. (2009) provided specific examples demonstrating the existence of a reliability paradox - that if one adds a road to a network, then all of the users may be worse off in terms of total expected network cost or travel time reliability.

- $\quad$ Szeto and Jiang (2014) pointed out that providing new lines to a transit network, or increasing the frequency of an existing line, may not improve the system performance in terms of expected total system travel cost.

- $\quad$ Yao and Chen (2014) examined the stochastic assignment paradox by which the total travel cost increases when an inferior travel alternative is marginally improved. Unlike Sheffi and Daganzo (1978), Yao and Chen extended this consideration to a weibit route choice model and to a hybrid model that considers both weibit and logit models.

The above paradox studies can roughly be classified into five types. The first type is mostly focused 
on "travel time" (or more generally, "travel cost") at the O-D or system levels, and considers the flowdependent travel time/cost function and Wardropian travel behavior. As long as the travel time is flow dependent, the Wardropian selfish travel behavior (that considers travel time at a personal level) leads to flow patterns that are not optimal in terms of O-D or system efficiency, and hence lead to various travel time- or cost-related "paradoxes" at the O-D or system levels. These paradoxes arise because travelers make decisions without taking into account their effects on the system or the O-D pair costs. Capacity is another characteristic of a link or network. Hence, the second type of study (e.g., Yang \& Bell, 1998; Daganzo, 1996) focuses on "capacity" or network throughput under the Wardropian selfish travel behavior assumption. Due to this assumption, the capacities of different critical links are sometimes independent and sometimes interdependent. The closure of a particular link can make the capacities of two critical links independent in some cases, increasing the network throughput. The third type of study is concerned with the reality that travel time may vary considerably due to supply or demand uncertainty. Thus, the third type of study extends the consideration to travel cost reliability (e.g., Szeto et al., 2009). The travelers are still assumed to follow Wardrop's first principle, and the performance measure is the expected total system cost, which is a reasonable generalization of total system travel time under uncertainty. The fourth type of study extends consideration to a dynamic version of the Wardropian first principle (e.g., Akamatsu, 2000; Zhang et al., 2008; Lin \& Lo, 2009), but total system travel time or cost is still the main consideration. The fifth type of study considers the stochastic extension (e.g., Sheffi \& Daganzo, 1978 and Yao \& Chen, 2014), but it is assumed that the main cause of the paradox is the randomness of perceived travel time, rather than unawareness concerning the effect of route choices on system or O-D costs.

In addition to the issues of total system travel time (and its cost) and the throughput as described above, the by-products of vehicular traffic, including emissions and noise, are also worthy of consideration. In recent years, as the discussion on sustainability has developed, the relationship between environment and transportation has increasingly become a hot topic of concern. The review by Szeto et al. (2012) pointed out that environmental sustainability is closely related to road transportation, because motor vehicles traveling on roads emit emissions and noise. Vehicle emissions have been closely associated with adverse effects on humans and the environment. For example, carbon monoxide $(\mathrm{CO})$, hydrocarbons $(\mathrm{HC})$, nitrogen oxides $\left(\mathrm{NO}_{\mathrm{x}}\right)$ and fine particular matter $\left(\mathrm{PM}_{10}\right)$ cause severe health problems, such as reducing lung function or inducing and aggravating asthma (Cappiello, 2002). Other environmental costs include damage to plants and reduction of crop yields (Mayeres et al., 1996). The adverse effects of "invisible" traffic noise have also been considered in some studies. A number of studies have shown that noise exposure can induce hearing impairment, hypertension, ischemic heart disease, annoyance, sleep disturbance and decreased school performance (Passchier-Vermeer \& Passchier, 2000). Motor vehicles are usually the primary source of noise disturbance in the home. Levinson et al. (1996) pointed out that the damages caused by noise are hard to quantify, but such damage is associated with particular places, and it is commonly viewed as a cause for decreases in property values. Delucchi and Hsu (1996) have indicated that noise is a sufficiently prominent problem that it measurably affects the value of homes. These researchers found that the cost of external damage directly caused by motor vehicle noise could reach as high as $\$ 40$ billion per year (1990 data, 1991 dollars). Hence, it is profoundly important to incorporate considerations for environmental sustainability into transportation network design.

Nagurney (2000a, 2000b) was the first to identify the paradoxical phenomena linked to the total emissions associated with congested urban transportation network design. She indicated that some "so-called improvements" to the network (e.g., an addition of a link) may result in an increase of total emissions generated. Szeto et al. (2008) investigated the simultaneous occurrence of this emission paradox and Braess' paradox. They concluded that the Braess and emission paradoxes do not always occur at the same time. There are certain circumstances where the emission paradox occurs, but the Braess paradox does not. This finding implies that the two paradoxes are different phenomena, and that deficiencies in the design of models for mitigating congestion alone may actually cause increases in vehicular emissions. However, in existing studies on the emission paradox, the vehicle emissions are calculated as a product of the corresponding emission factor and the link flow, with the emission factor of each link assumed to be constant. In actuality, emission factors should depend not only on 
the distance traveled, but also on a number of other factors including vehicle type and age mix, vehicle speed, operating mode, and time of day of travel, as was pointed out by DeCorla-Souza et al. (1994). Moreover, the emission factors are convex functions of speed in general (Oneyama et al., 2001; Patil et al., 2009). That makes it obvious that emission paradox and Braess' paradox are not supposed to occur simultaneously, because Braess' paradox is strongly correlated to nonincreasing cost functions (Roughgarden, 2005), differing from the non-monotone function of speed in emission estimation. Hence, it is critical to have an accurate estimation of vehicular emissions for the development of transportation network design with emission consideration (Sharma \& Mathew, 2007), and some progress should be made in emission paradox research. More importantly, although noise is also a by-product of vehicular traffic and is harmful to humans and the environment, to the best of our knowledge no research has been conducted to analyze the existence of paradoxical phenomena in the relation between noise and congested urban transportation network design.

This study explores an analogue to the previously observed paradoxes, namely an excessive noise paradox. This counterintuitive phenomenon can be defined as follows: in a static traffic assignment with non-cooperative behavior of travelers, some traffic control strategies or network improvements can cause the total amount of excessive noise (and its cost) to increase. We carry out sensitivity analyses to demonstrate the occurrence of an excessive noise paradox arising from travel demand, link function parameters and speed limits. In addition, the simultaneous occurrences among the excessive noise paradox, the emission paradox, and the Braess paradox are identified and examined.

The main contribution of this study is its introduction and examination of the newly identified excessive noise paradox. In particular, this analysis illustrates that excessive noise, emissions and Braess paradoxes may occur either together or separately. This finding implies the need for a more comprehensive approach to network design that considers noise, emissions, and total travel time simultaneously. This study also contributes to the literature on the existence of emission paradoxes by offering more accurate emission estimates through the use of macroscopic emission models, rather than through calculations of constant emission factors.

The remainder of this study is organized as follows. Section 2 briefly introduces vehicle emission and general noise-cost models, which are foundational for discovering the existence of the emission and excessive noise paradoxes. Section 3 defines the excessive noise paradox. Section 4 depicts three counterintuitive phenomena with respect to excessive traffic noise. The existence of these phenomena is illustrated and briefly explained using examples from several small networks. In examining these networks, the potential for simultaneous occurrences among the excessive noise paradox, the emission paradox and the Braess paradox is demonstrated. Finally, Section 5 offers a number of practical insights for solving future transportation problems.

\section{VEHICLE EMISSION AND NOISE MODELS}

This section introduces the vehicle emission model developed by Penic and Upchurch (1992) and a general noise-cost model developed by Delucchi and Hsu (1996). These models serve as foundations for the identification of paradoxical phenomena in Section 3.

\subsection{Vehicle emission model}

The effort to specify levels of automobile emissions can be traced back to the 1960s (Soltau \& Campbell, 1968; Jackson et al., 1969). Since that time, researchers have been industriously contributing to the development of models for estimating vehicle emissions. These models can be roughly divided into a) macroscopic and microscopic models (depending on how vehicular activities are aggregated over space and time (Nie \& $\mathrm{Li}, 2013)$ ), or b) aggregated, static, and dynamic emission models (according to their ways of considering congestion (Smit et al., 2008; Szeto et al., 2012)). In this study, the link travel speed is an important consideration in estimating the amount of emissions. 
Penic and Upchurch (1992) proposed a macroscopic average-speed model, based on fuel consumption and calibrated from empirical data. In their model, the rate of production ( $R O P, \mathrm{~g} / \mathrm{veh}$-feet) of pollutant $p$ on link $a$ varies nonlinearly with the link average travel speed $v_{a}(\mathrm{ft} / \mathrm{sec})$ :

$$
\operatorname{ROP}_{a}^{p}=\frac{A^{p} e^{B^{p} v_{a}}}{C^{p} v_{a}}, \forall a, p,
$$

where $A^{p}, B^{p}$ and $C^{p}$ are constant coefficients for pollutant $p$. To illustrate how $R O P$ changes with speed, the following plot is provided:

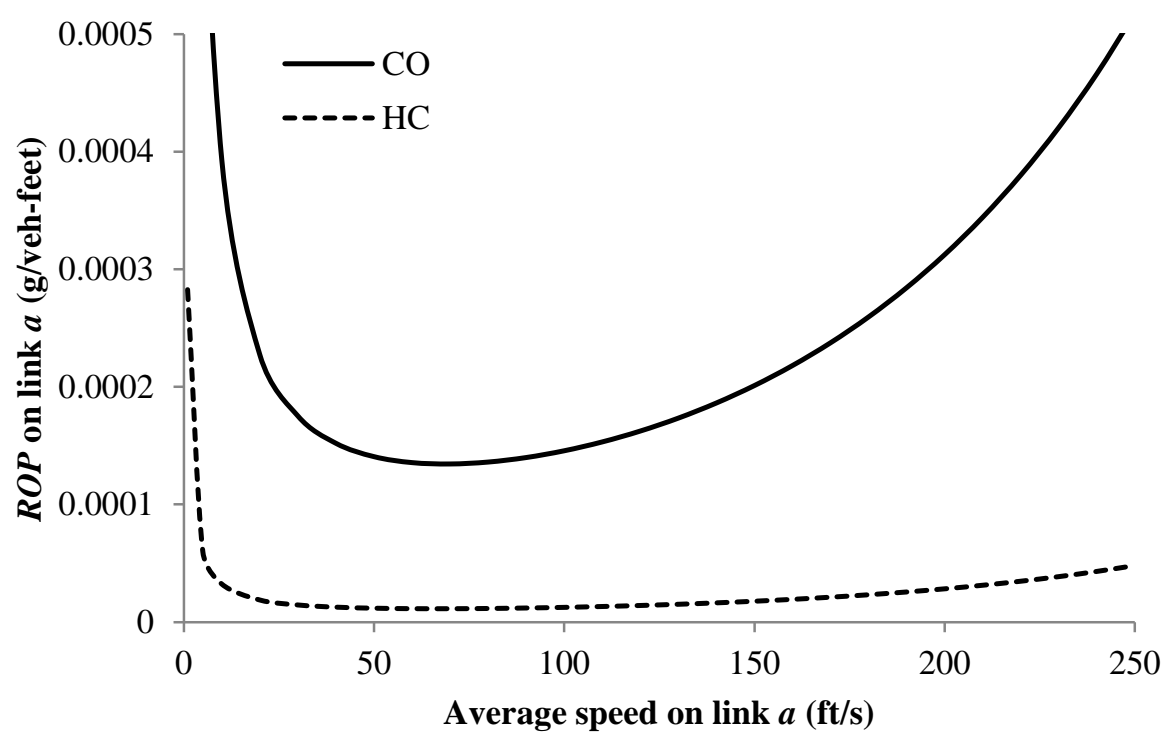

Figure $1 R O P$ versus travel speed

It is worth noticing that there is an optimum speed at which the rate of production of certain pollutant reaches the minimum (e.g. approximately $70 \mathrm{ft} / \mathrm{s}$ for CO). Then, the hourly emission $Q_{a}^{p}(\mathrm{~g} / \mathrm{hr})$ for pollutant $p$ on link $a$ is calculated by multiplying its emission rate $R O P$ by the link traffic flow $x_{a}$ $(\mathrm{veh} / \mathrm{hr})$ and the distance traveled, which is equal to the length of the link $l_{a}(\mathrm{ft})$ in a network:

$$
Q_{a}^{p}=R O P_{a}^{p} \cdot l_{a} \cdot x_{a}, \forall a, p
$$

The hourly total emission cost associated with the transportation network, denoted by $T E C$, is then computed by multiplying $Q_{a}^{p}$ and its monetary value $\phi^{p}(\$ / \mathrm{g})$. That is,

$$
T E C=\sum_{a} \sum_{p} Q_{a}^{p} \cdot \phi^{p}
$$

Note that average speed models provide more accurate emission estimations than constant emission factor models, and they interface with transportation models conveniently. However, average speed models do not consider accelerations or decelerations, which also have effects on emissions. Nevertheless, owing to their merits of being computationally tractable and scalable, these models are commonly used in transportation planning studies (e.g., Benedek \& Rilett, 1998; Yin \& Lawphongpanich, 2006; Nagurney et al., 2010; Li et al., 2012).

In this study, carbon monoxide (CO) and hydrocarbons ( $\mathrm{HC}$ ) are chosen as examples for emission cost estimation. The parameters for CO and HC are obtained from Penic and Upchurch (1992) and are 
listed in Table 1. The monetary valuation factors $\phi^{p}$ are excerpted from Matthews (1999) and are converted to U.S. currency at its 1991 value.

Table 1 Coefficients and monetary valuations of different pollutants

\begin{tabular}{|c|c|c|}
\hline & $\mathrm{CO}$ & $\mathrm{HC}$ \\
\hline $\mathrm{A}$ & 3.3963 & 2.7843 \\
\hline $\mathrm{B}$ & 0.014561 & 0.015062 \\
\hline $\mathrm{C}$ & 1000 & 10000 \\
\hline$\phi^{p}(1991$ \$gram $)$ & 0.00051 & 0.00136 \\
\hline
\end{tabular}

\subsection{General noise-cost model}

The estimations of noise levels and the damage costs caused by noise in terms of monetary values (i.e., noise cost) are both fundamental for modeling the economic damage of traffic noise pollution. Many studies have been carried out to develop a predictive traffic noise model (TNM), and there are some commonly used TNMs, such as the U.S. FHWA (Federal Highway Administration) highway traffic noise prediction model, the FHWA TNM version 1.0, the British CoRTN procedure (Calculation of Road Traffic Noise) (Department of Transport, 1988) and the German RLS 90 (Richtlinien für den Lärmschutz an Straßen) TNM. All of these models distinguish between different vehicle types. Most of them use simple traffic streams as noise sources, and then adopt the equivalent sound level $L_{e q}$ as the acoustic energy descriptor. These models differ slightly in aspects such as input data, type of mapping between the noise source and receptor and consideration of noise propagation. The main features, peculiarities and detailed formulations of each TNM are explained in the thorough reviews conducted by Steele (2001) and by Quartieri et al. (2009). Meanwhile, there has been a continuous effort by researchers to monetize the damage that has been caused by traffic noise over the years (e.g., Bagby, 1980; Nelson, 1982; Modra \& Bennett, 1985; Delucchi \& Hsu, 1996; Haling \& Cohen, 1996; FHWA, 1997; Forkenbrock, 1999; Bateman et al., 2001; Maibach et al., 2008). Most of these studies have used hedonic pricing methods to relate noise reduction to the increase of residential property value, or vice versa. Some of the studies express this relationship as a ratio of reduction in property value per (excess) noise level, which is referred to as a property depreciation index.

However, the research on developing integrated noise models (which seeks to combine noise level estimation and noise cost models (e.g., Fuller et al., 1983; Levinson et al., 1996; Delucchi \& Hsu, 1996)) remains insufficient. The integrated noise model is complex, and it requires the combination of a number of equations (Levinson et al., 1996). Fuller et al. (1983) proposed a general noise-cost model for calculating the cost of traffic noise as a product of the housing units in each noise band, each level of excessive noise and the property depreciation index. The core of this general noise-cost model is the calculation of area-noise levels. The model adopts a 1970s-vintage noise generation function for noise level estimation, and delineates three noise bands. The average noise level for each band is used for calculating total noise levels along the road. It is reported that the results of the 1983 study by Fuller et al. have been cited in virtually every review on the social costs of transportation in the U.S. (Delucchi \& Hsu, 1996). Hence, an improved, expanded and updated version of the Fuller $e t$ al. (1983) model, as developed by Delucchi and Hsu (1996), is adopted as the foundation for identifying the excessive noise paradox.

One may argue that there is no well-accepted noise cost model that functions like the Bureau of Public Roads (BPR) model for traffic assignment, and that the exact occurrence of an excessive noise paradox depends on the functional form and values of its parameters. However, the main purpose of this study is to introduce and establish the existence of an excessive noise paradox. The exact functional form and its parameter values are of less importance. So long as the noise model used for illustration can produce correct trends of the noise levels/costs that follow when the essential noisecontributing factors (e.g., speed or traffic mix) increase their values, the conclusions of this study are still valid. Moreover, the method of analysis is still applicable if other noise models (including those 
that capture the costs of noise for wildlife) are used. Note also that similar arguments apply to the emission paradox.

The general noise-cost model proposed by Delucchi and Hsu (1996) adopts the TNM as used in the FHWA's developed speed-based TNM. This approach is recognized as one of the most commonly used noise prediction models in the review by Steele (2001). The accuracy of area-noise level estimation is improved by integrating the updated noise-generation equation over the area exposed to excessive noise with infinite noise bands. With this integrated model, the effects of excessive traffic noise (above a certain threshold) can be measured in terms of how much each additional decibel of noise reduces the residential property values. To simplify the application of this model to our network scenario, it is assumed that the road type and the noise barrier height are homogeneous within the tested urbanized network.

The total cost of damage from excessive traffic noise (TNC) that comes directly from motor vehicles is formulated as follows:

$$
T N C=\left(\sum_{a} A N_{a}\right) \cdot M \cdot P \cdot H V \cdot \frac{T_{o}+T_{i}}{T_{i}},
$$

where $M$ (units $/ \mathrm{mi}^{2}$ ) is the density of housing units exposed to the excessive noise, $P$ ( $\$ /$ unit) is the median annualized value of housing units exposed to the excessive noise, and $H V$ is the percentage of housing value diminution per excessive decibel of noise. This parameter is really valid only over the range of noise problems experienced in those housing areas studied in the original hedonic-price analyses (Delucchi \& Hsu, 1996). Therefore, if an area experiences significantly different noise problems from those found in the residential areas, the function might not give an accurate assessment of the noise cost in that area. Delucchi and Hsu (1996) recognize this limitation of the model, and state that they lack of the data to adjust it. Nevertheless, a trivial total cost (less than $\$ 10$ million in their base case) is estimated for the noise damage in non-urbanized areas. $T_{i}(\mathrm{~min})$ is the average time spent in or around one's home, and $T_{o}$ is the average time away from one's home in places where motor-vehicle noise can be a problem.

$A N_{a}\left(\mathrm{dBA}-\mathrm{mi}^{2}\right)$ in Equation (4) is the excessive traffic "area-noise level" associated with link $a$, which can be obtained as follows:

$$
A N_{a}=\frac{l_{a}^{\prime}}{5280} \cdot\left(\left(\int_{d_{e, a}}^{d_{t^{*}, a}} L_{e q_{a}}(w) d w\right)-A N B_{a}\right), \forall a,
$$

where $L_{e q_{a}}\left(d_{a}\right)$ denotes the "equivalent sound level" for vehicle noise associated with link $a$, which is a function of distance $d_{a} . A N B_{a}(\mathrm{dBA}-\mathrm{ft})$ is the "area-noise" level below the noise-damage threshold $t^{*}$ (dBA). $l_{a}{ }^{\prime}$ (mi) is the length of link $a . d_{e, a}$ is the distance to the closest housing unit from link $a$. $d_{t^{*}, a}$ is the distance from link $a$ (where the noise level drops off) to the threshold level. The approach to calculating $A N_{a}$ is as follows: first, integrate $L_{e q_{a}}(\mathrm{dBA})$ with respect to the distance $d_{a}(\mathrm{ft})$ to obtain the total noise level over the entire affected area. Then subtract $A N B_{a}$ from this integration to obtain the excess noise level over this affected area. Finally, multiply the result by the total length $l_{a}^{\prime}$. $A N_{a}$ (i.e., $\mathrm{dBA}-\mathrm{mi}^{2}$ ) can be interpreted as the area of land subject to some true average noise level (Delucchi \& Hsu, 1996). 
Figure 2 shows the definitions of $A N_{a}$ and $L e q_{a}\left(d_{a}\right)$ in a more intuitive way. $A N_{a}$ is the shaded volume, indicated in the figure. It can be seen that the function for integration (i.e., $\operatorname{Leq}_{a}\left(d_{a}\right)$ ) is a function of distance $d_{a}$, which decreases from the road center until it finally drops off to the threshold level $t^{*}$ at some point. It is presumed that the noise level below this threshold causes zero damage (Delucchi \& Hsu, 1996). Hence, the integral volume is evaluated from the distance of the closest housing unit (the point $d_{e, a}$ ) to the distance at which the noise falls below the threshold level (the point $\left.d_{t^{*}, a}\right)$, and $A N B_{a}$ is equal to $t^{*} \cdot\left(d_{t^{*}, a}-d_{e, a}\right)$. For each road with its own vehicle flow and average vehicle speed, $d_{t^{*}, a}(\mathrm{ft})$ can be obtained by solving $L_{e q_{a}}\left(d_{t^{*}, a}\right)=t^{*}$.

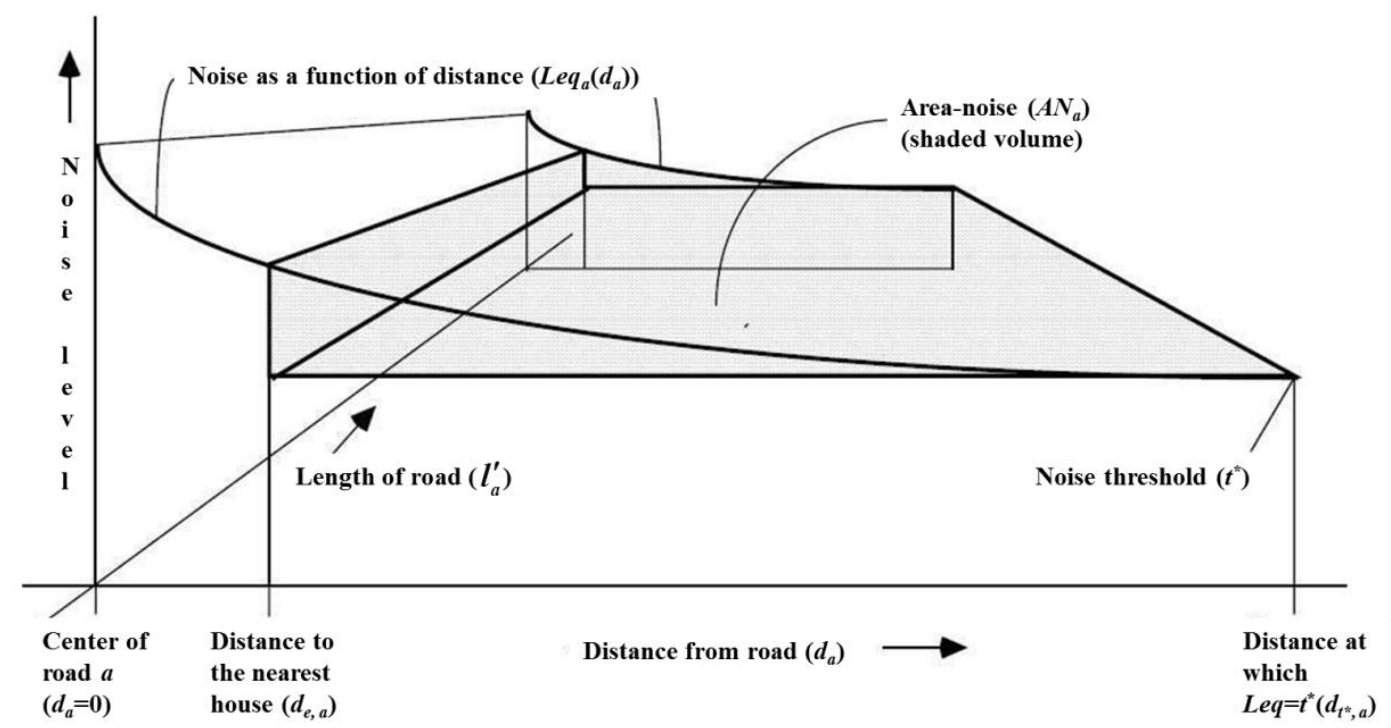

Figure 2 Area-noise level and equivalent sound level associated with link $a$ (modified from Delucchi \& Hsu, 1996)

The equivalent sound level function in (5) is a simplified version of the FHWA TNM with an addition of a noise barrier reduction term $B_{a}$ by Delucchi and Hsu (1996), which is defined as

$$
L_{e q_{a}}\left(d_{a}\right)=10 \cdot \log _{10}\left(0.0296 \cdot \frac{\varphi^{\prime}}{180} \cdot x_{a} \cdot K_{a} \cdot\left(\frac{50}{d_{a}}\right)^{1+\alpha}\right)-B_{a}, \forall a,
$$

where $\varphi^{\prime}$ is the equivalent subtending angle used to model the decrease in the noise level caused by incomplete obstructions. $x_{a}(\mathrm{veh} / \mathrm{hr})$ is the traffic flow on link $a . \alpha$ is a unitless ground-cover coefficient. $B_{a}(\mathrm{dBA})$ is the reduction in noise level provided by a noise barrier, if there is any on link $a$. $K_{a}$ is the total noise-energy emissions associated with link $a$, depending on the different vehicle types and the average vehicle speed $v_{a}^{\prime}(\mathrm{mph})$ :

$$
K_{a}=\frac{F_{a}}{v_{a}^{\prime}} \cdot\left(v_{a}^{\prime 4.174} \cdot 10^{0.115}+10^{G_{a}}\right), \forall a
$$

The above equation and exponents are drawn from the FHWA's transportation noise model. The fraction $F_{a}$ in Equation (7) is the proportion of the vehicle type considered in the main traffic stream of link $a$. For simplicity, this study assumes that all of the vehicles considered are light-duty 
automobiles, and hence $F_{a}$ equals one. The exponent $G_{a}$ is the parameter that accounts for the fractions of vehicles cruising and accelerating on link $a$.

It can be seen from Equations (6) and (7) that this general noise-cost model interfaces with the traffic model, whereby traffic flow and average speed are required as inputs. Given the traffic flow on each link, the average speed is determined by dividing the length of the link by the travel time. A widely used link performance function developed by the BPR is adopted to evaluate the travel time on the link in this study, which is stated as follows:

$$
t_{a}\left(x_{a}\right)=t_{0}^{a} \cdot\left[1+\beta \cdot\left(\frac{x_{a}}{C_{a}}\right)^{n}\right],
$$

where $t_{a}\left(x_{a}\right), t_{0}^{a}$, and $x_{a}$, are respectively the average travel time, the free flow travel time, and the flow on link $a$; $C_{a}$ denotes the practical capacity of link $a$, and equals 0.75 of actual capacity (Khisty, 2003). $\beta$ and $n$ are calibration parameters, whose default values are 0.15 and 4 , respectively. The free flow travel time is equal to $l_{a}$ divided by its free flow travel speed $v_{0}^{a}$ :

$$
t_{0}^{a}=\frac{l_{a}}{v_{0}^{a}}
$$

Equations (6)-(9) express the relation between the equivalent noise level and travel speed. Figure 3 is provided to illustrate how the equivalent noise level changes with average speed on a link ranging from optimal speed (where link flow equals to actual capacity) and free flow speed $(60 \mathrm{~km} / \mathrm{hr}$, i.e., $37.28 \mathrm{mph}$, assumed in this study). The relationship between link flow and average link speed is embodied within this plot, with the default values of $\beta$ and $n$ being used. The speed range is also consistent with the modeling assumption of classical static traffic assignment that travel time is monotonically increasing with link flow.

It can be observed from Figure 3 that $L_{e q}$ firstly increases gradually and then decreases with link average speed within this region. When the speed starts from optimal speed, where link flow saturates the actual link capacity, $L_{e q}$ is relatively low. When the speed further increases, the corresponding link flow decreases at the same time, which both are prominent parameters in the $L_{e q}$ calculation. The sharp drop in the end is resulted by extremely small link flow when the speed is close to free-flow speed.

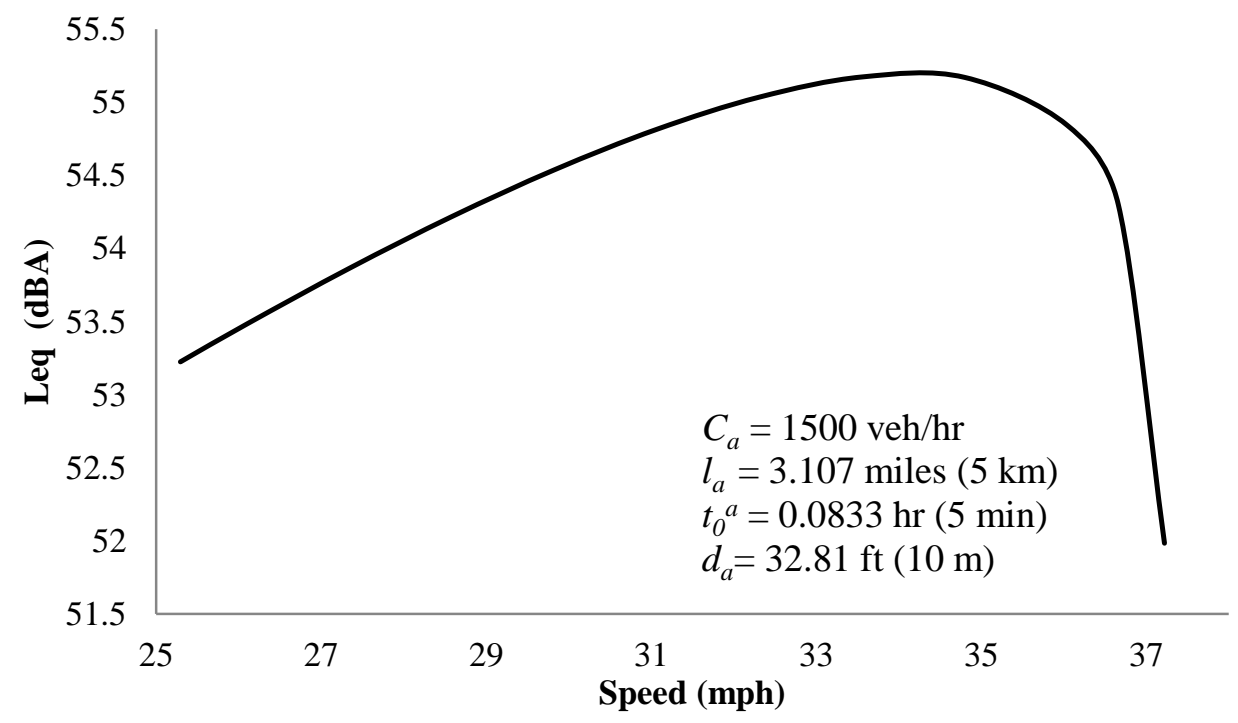


Figure 3 Noise level versus travel speed (light-duty automobiles only)

In the study by Delucchi and Hsu (1996), the TNC is calculated for each of six different types of road in each of 377 urbanized areas, based on detailed data for housing values, housing density, roadway mileage and roadway traffic in each area. Due to the lack of detailed data for rural areas, a trivial total cost (less than $\$ 10$ million) is calculated for one aggregated rural area. For this reason, this model appears to underestimate the noise cost in rural areas.

All of the parameter values involved in this study can be seen in Table 2 below. The econometric parameters are extracted from the 1990-1991 data from Sioux Falls, South Dakota, USA, which is a network frequently used in analyses of transportation problems.

Table 2 Values of parameters selected from Delucchi and Hsu (1996)

\begin{tabular}{|c|c|c|c|c|c|c|c|c|c|c|c|}
\hline Symbol & $\varphi^{\prime}$ & $G_{a}$ & $\alpha$ & $B_{a}$ & $d_{e, a}$ & $t^{*}$ & $H V$ & $T_{i}$ & $T_{o}$ & $M$ & $P$ \\
\hline Unit & $\mathrm{deg}$ & $\mathrm{Nil}$ & $\mathrm{Nil}$ & $\mathrm{dBA}$ & $\mathrm{ft}$ & $\mathrm{dBA}$ & $\mathrm{Nil}$ & $\mathrm{min}$ & $\mathrm{min}$ & units/mi & \$/unit \\
\hline Value(s) & 59 & 5.1 & 0.375 & 8.4 & 33.5 & 55 & 0.0085 & 921.1 & 250.6 & 1290.8 & 59100 \\
\hline
\end{tabular}

The parameters in the general-noise cost model do not involve demographic or driving behavior parameters. The parameters involved can be divided into two groups: housing-related parameters (such as housing density $M$, housing values $P$, depreciation index $H V$ and threshold $t^{*}$ ) and traffic or environs-related parameters (equivalent subtending angle $\varphi^{\prime}$, noise reduction by barriers $B_{a}$, ground-cover coefficient $\alpha$, and the parameter that accounts for the proportions of vehicles cruising or accelerating $G_{a}$ ).

For the first group of parameters, the original report by Delucchi and Hsu (1996) stated that "Ideally, one would estimate annualized housing value just as one would estimate housing density, as a function of proximity to and traffic flow of each type of road in each urbanized area. However, there are no data on annualized housing values along specific types of roads." Hence, the values for the parameters are assumed to be uniform within a city. The estimated values are available from the Bureau of the Census (1990a, 1990b) and are provided in the separate Appendix to the report (Delucchi \& Hsu, 1996). The data on Sioux Falls is adopted to illustrate the estimation of excessive noise damage corresponding to a selected network. Nevertheless, these data can be replaced by any other city's data without affecting the conclusion.

For the second group of parameters associated with roadway topology or traffic, their influences on the noise costs are shown in the sensitivity analysis in the study by Delucchi and Hsu (1996) (Table 14-8, p. 58). It is reported that the total costs are not sensitive to changes in these parameters (i.e., most of the parameters change the total cost by less than $10 \%$, except for the parameters of subtending angle $\varphi(36.2 \%)$ and ground-cover coefficient $\alpha(21.6 \%))$. In this study, these parameters are assigned with appropriate calibrated values from the research by Delucchi and Hsu (1996).

Note that housing density has nothing to do with the transportation network, but the noise cost also depends on noise levels, which in turn depend on traffic conditions such as speed (which in turn depends on travel time), traffic mix and network characteristics such as gradient, length and road surface type. In other words, the existence of the excessive noise paradox as introduced in the next section is related to the transportation network and its characteristics.

\section{EXCESSIVE NOISE PARADOX}

In this section, the occurrence of the counterintuitive excessive noise paradox and the simultaneous 
occurrences among the emission paradox, Braess' paradox and excessive noise paradox are demonstrated by using three small network examples. The excessive noise paradox is defined as follows: in traffic assignment with non-cooperative behavior of travelers, some traffic control strategies or network improvements can cause the total amount of excessive noise (and its cost) to increase. The three examples given are associated with demand control, new link addition and speed limit implementation under a fixed demand assumption. Travelers are also assumed to select routes according to the user equilibrium (UE) principle. Hence, the link flows in each example are obtained by solving the corresponding UE traffic assignment problem.

\subsection{Paradox 1: A decrease in travel demand may result in an increase in total excessive noise (and its cost)}

As depicted in Figure 4, the example network includes three links and three nodes. The link cost function (BPR function) and the practical link capacity are shown in Table 3. Free flow travel time can be calculated by the free flow travel speed and the length of the link. There are two origindestination (O-D) pairs: from node 1 to node 3 with fixed demand $D_{1,3}$, and from node 1 to node 2 with a demand of $D_{1,2}$. Note that the two paths, $p_{1}=(d, b)$ and $p_{2}=(c)$, connect O-D pair $(1,3)$, but there is only one path for O-D pair $(1,2)$.

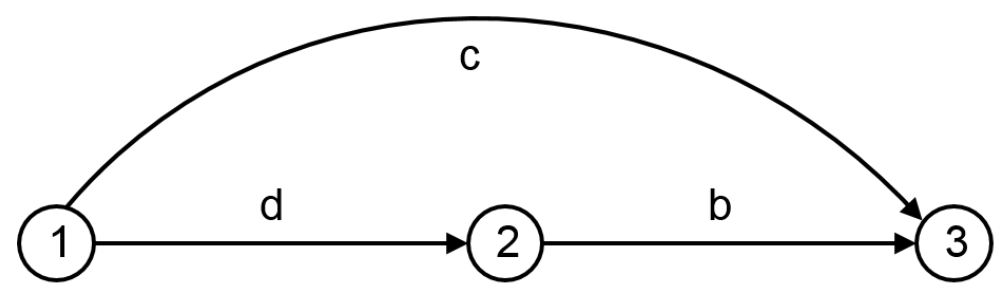

Figure 4 Network topology for Paradox 1

Table 3 Input data to the example for Paradox 1

\begin{tabular}{|l|c|c|c|}
\hline \multirow{2}{*}{} & \multicolumn{3}{|c|}{ Link } \\
\cline { 2 - 4 } & $d$ & $b$ & $c$ \\
\hline Link free flow travel speed & \multicolumn{3}{|c|}{$37.28 \mathrm{mph}(60 \mathrm{~km} / \mathrm{hr})$} \\
\hline Link length & $\begin{array}{c}1.864 \mathrm{miles} \\
(3000 \mathrm{~m})\end{array}$ & $\begin{array}{c}1.243 \mathrm{miles} \\
(2000 \mathrm{~m})\end{array}$ & $\begin{array}{c}3.418 \mathrm{miles} \\
(5500 \mathrm{~m})\end{array}$ \\
\hline Link practical capacity (veh/hr) & 1500 & 2500 & 2500 \\
\hline Link cost function parameters & \multicolumn{3}{|c|}{$\beta=0.15, n=4$} \\
\hline
\end{tabular}

Originally, the travel demands are $D_{1,2}=500 \mathrm{veh} / \mathrm{hr}$ and $D_{1,3}=1500 \mathrm{veh} / \mathrm{hr}$, respectively. The traffic equilibrium link flow pattern is $x_{d}^{*}=1530 \mathrm{veh} / \mathrm{hr}, x_{b}^{*}=1030 \mathrm{veh} / \mathrm{hr}$, and $x_{c}^{*}=470 \mathrm{veh} / \mathrm{hr}$. The total amount of excessive noise generated is $0.00031 \mathrm{dBA}-\mathrm{mi}^{2}$, resulting in a damage cost of $\$ 255.704$ to house values. It is noticed that the excessive traffic noise (and its cost) is mainly attributable to link $b$, because: firstly, the average travel speed on link $d$ is relatively low at this point, resulting in little amount of excessive noise damage. Secondly, the noise level below a certain threshold causes zero damage to the surrounding living environment (Delucchi \& Hsu, 1996). The traffic flow on link $c$ is relatively small, leading to low equivalent noise levels and no excessive noise damage.

Now, if $D_{1,2}$ falls to $100 \mathrm{veh} / \mathrm{hr}$ and all of the other settings remain the same, the new traffic equilibrium link flow pattern is $x_{d}^{*}=1513 \mathrm{veh} / \mathrm{hr}, x_{b}^{*}=1413 \mathrm{veh} / \mathrm{hr}$, and $x_{c}^{*}=87 \mathrm{veh} / \mathrm{hr}$. The total amount of excessive noise generated becomes $0.00369 \mathrm{dBA}-\mathrm{mi}^{2}$. The total damage cost also rises, to $\$ 3041.86$, which is increased by more than 10 times. If $D_{1,2}$ begins to decrease but $D_{1,3}$ remains the 
same, the link travel time cost of link $d$ is reduced, because there is less traffic flow on this link, and the path travel time cost (calculated as $p_{1}=(d, b)$ ) is reduced as well. To reach a new traffic equilibrium, a portion of the traffic flow of O-D pair $(1,3)$ is diverted from $p_{2}$ onto $p_{1}$. This diversion slightly helps to alleviate the traffic condition on link $c$ and reduces the noise amount/cost, but it induces much higher traffic flow and a much larger amount of noise cost associated with link $b$. Meanwhile, link $c$ still gives zero excessive noise cost due to even lower link flow. As a result, the amount of excessive traffic noise generated on link $b$ increases and overweighs the decreased amount by link $d$, and the total damage cost of excessive noise rises.

To gain an idea of the excessive noise generated by the system optimal traffic flow, the corresponding link flow pattern with $D_{1,2}=100 \mathrm{veh} / \mathrm{hr}$ is calculated: $x_{d}^{*}=1040 \mathrm{veh} / \mathrm{hr}, x_{b}^{*}=940 \mathrm{veh} / \mathrm{hr}$, and $x_{c}^{*}=$ $560 \mathrm{veh} / \mathrm{hr}$. The total amount of excessive noise generated is zero $\mathrm{dBA}-\mathrm{mi}^{2}$, which is less than $0.00369 \mathrm{dBA}-\mathrm{mi}^{2}$ under UE.

To illustrate the occurrence of this paradox in a real large road network, the frequently used Sioux Falls network is selected. The detailed configuration, together with the demand matrix, can be found on the website provided by Bar-Gera (2012). The network topology is provided in Figure 5 below.

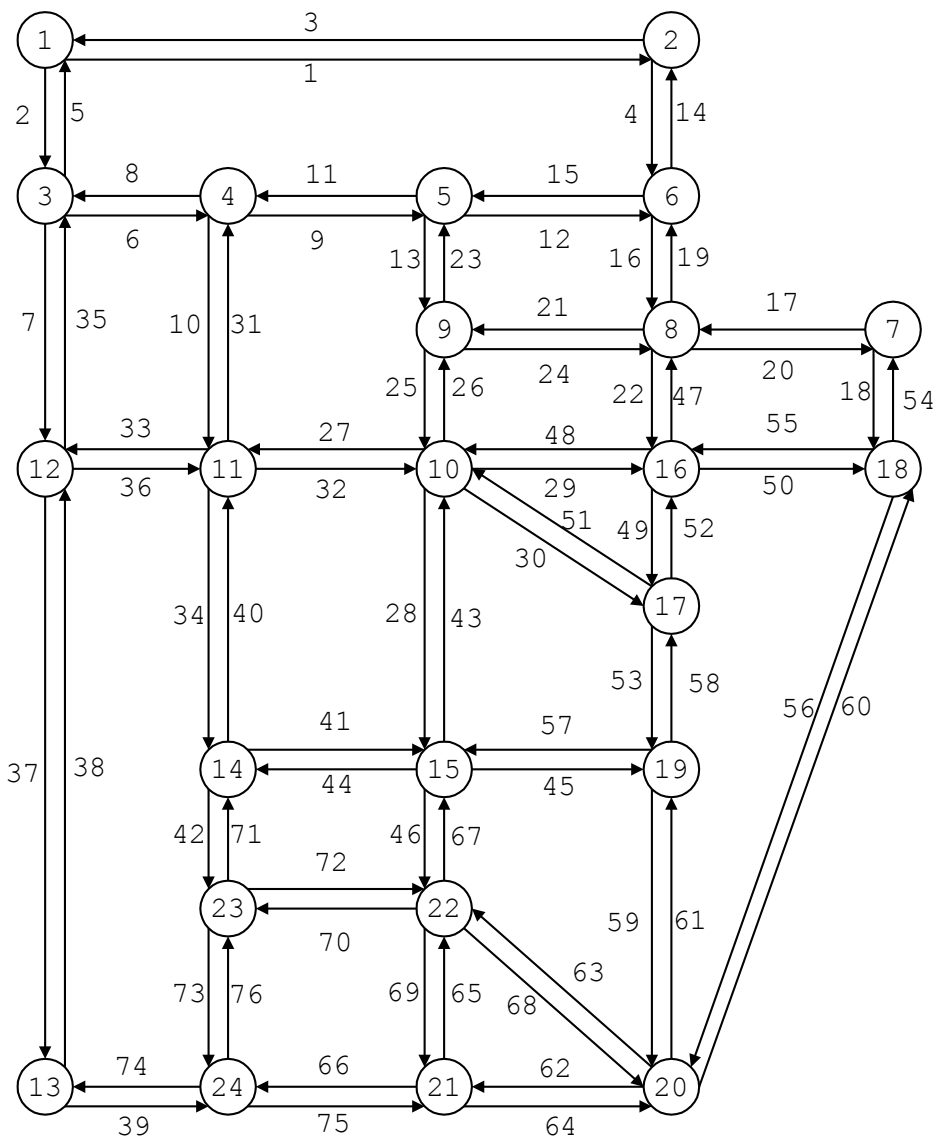

Figure 5 Sioux Falls network topology for Paradox 1

To start with, the O-D traffic demands are loaded onto the network with a few changes $\left(D_{15,16}=0\right.$, $D_{17,16}=0, D_{19,16}=0, D_{20,16}=0$, and $\left.D_{21,16}=0\right)$. The travel demand for the O-D pair $(17,10)$ is 3900 veh/hour initially. At UE, the total amount of excessive noise generated is $14.787 \mathrm{dBA}-\mathrm{mi}^{2}$, which equals a damage cost of $\$ 12192421.43$ (in terms of property values). Now if the travel demand of OD pair $(17,10)$ falls to zero and the whole network traffic achieves a new equilibrium link flow pattern, the total amount of excessive noise generated increases to $14.892 \mathrm{dBA}-\mathrm{mi}^{2}$. The total damage cost also rises to $\$ 12278997.76$. 

in total excessive noise (and its cost) and in emissions (and their costs)

In this study, it is assumed that all vehicles travel at their allowable maximum speeds. Consider the network discussed in Paradox 1, with all of the settings remaining the same. By assigning $D_{1,2}=500$ $\mathrm{veh} / \mathrm{hr}$ and $D_{1,3}=1500 \mathrm{veh} / \mathrm{hr}$ into the network again, we have the same traffic equilibrium link flow pattern, with the total noise generated being $0.00031 \mathrm{dBA}-\mathrm{mi}^{2}$ and the damage cost being $\$ 255.704$. The weights of $\mathrm{CO}$ and $\mathrm{HC}$ emissions from the network are $4256.248 \mathrm{~g}$ and $357.915 \mathrm{~g}$, respectively, which correspondingly cause hourly damage costs of $\$ 2.171$ and $\$ 0.487$.

If a speed limit of $40 \mathrm{~km} / \mathrm{hr}$ is implemented on link $c$, and the free flow travel speed on all other links remains at $60 \mathrm{~km} / \mathrm{hr}$, then the free flow travel time on link $c$ is raised. The new traffic equilibrium link flow pattern is obtained as follows: $x_{d}^{*}=2000 \mathrm{veh} / \mathrm{hr}, x_{b}^{*}=1500$, and $x_{c}^{*}=0 \mathrm{veh} / \mathrm{hr}$. The total amount of excessive noise generated increases to $0.00454 \mathrm{dBA}^{-\mathrm{mi}^{2}}$, and the damage cost increases to \$3746.07. The emitted CO and HC also increase to $4454.119 \mathrm{~g}$ and $372.946 \mathrm{~g}$, respectively, which brings larger hourly costs of $\$ 2.271$ and $\$ 0.507$. The paradoxes of excessive noise and emissions occur simultaneously.

The explanation for this excessive noise paradox is similar to that for Paradox 1. When link $c$ has a speed limit, the free flow travel time increases, and the travel time cost through the link increases. This again leads to the traffic flow being redirected from link $c$ onto route $p_{1}=(d, b)$. If we recall that at this point the excessive noise is produced mostly by link $b$, the link flow increment of link $b$ results in the excessive noise increase, and the paradox occurs.

\subsection{Paradox 3: With a fixed demand, the addition of a link may result in increases of total excessive noise (and its cost) and of system travel time cost.}

Recall the classic Braess network (see Figure 6). The modified link cost function parameters are shown in Table 4 . There is only one O-D pair: OD pair $(1,4)$. Three routes are available after the new link addition, namely route 1 (1-2-4), route $2(1-3-4)$ and route 3 (1-2-3-4). Before link $(2,3)$ is added, the demand is equally loaded onto routes 1 and 2 , because the network is symmetric.

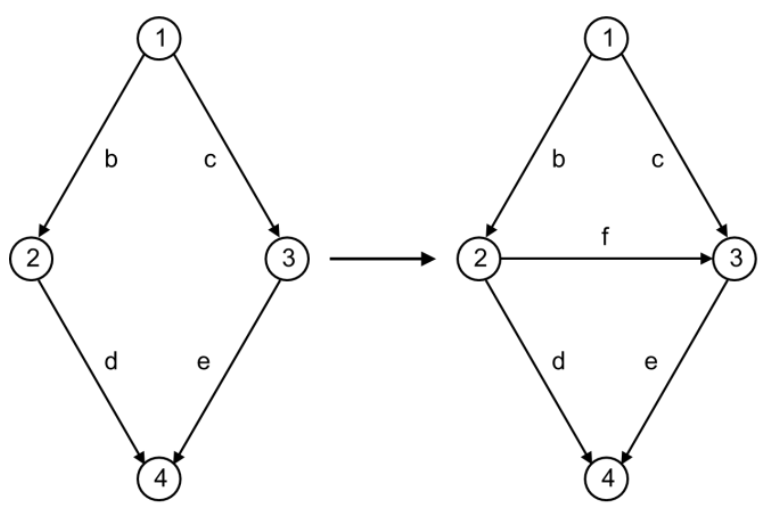

Figure 6 The Braess network

Figure 7 depicts the change in equilibrium path flows when total demand increases. It can be seen that initially, only route 3 (the dashed line) containing the new link carries the traffic flow. As the total demand increases (i.e., larger than $2543 \mathrm{veh} / \mathrm{hr}$ ), all routes begin to share traffic flows. Finally, the demand is too large, and only routes 1 and 2 carry traffic, which results in no contribution from the new link addition. 
Table 4 Input data to the example for Paradox 3

\begin{tabular}{|l|c|c|c|c|c|}
\hline & \multicolumn{5}{|c|}{ Link } \\
\cline { 2 - 6 } & $b$ & $c$ & $d$ & $e$ & $f$ \\
\hline Link free flow travel speed & \multicolumn{5}{|c|}{$37.28 \mathrm{mph}(60 \mathrm{~km} / \mathrm{hr})$} \\
\hline Link length & $\begin{array}{c}1.243 \\
\text { miles } \\
(2000 \mathrm{~m})\end{array}$ & $\begin{array}{c}3.355 \\
\text { miles } \\
(5400 \mathrm{~m})\end{array}$ & $\begin{array}{c}3.355 \\
\text { miles } \\
(5400 \mathrm{~m})\end{array}$ & $\begin{array}{c}1.243 \\
\text { miles } \\
(2000 \mathrm{~m})\end{array}$ & $\begin{array}{c}3.355 \\
\text { miles } \\
(5400 \mathrm{~m})\end{array}$ \\
\hline $\begin{array}{l}\text { Link practical capacity } \\
\text { (veh/hr) }\end{array}$ & 2000 & 5000 & 5000 & 2000 & 2200 \\
\hline Link cost function parameters & \multicolumn{5}{|c|}{$\beta=0.15, n=4$} \\
\hline
\end{tabular}

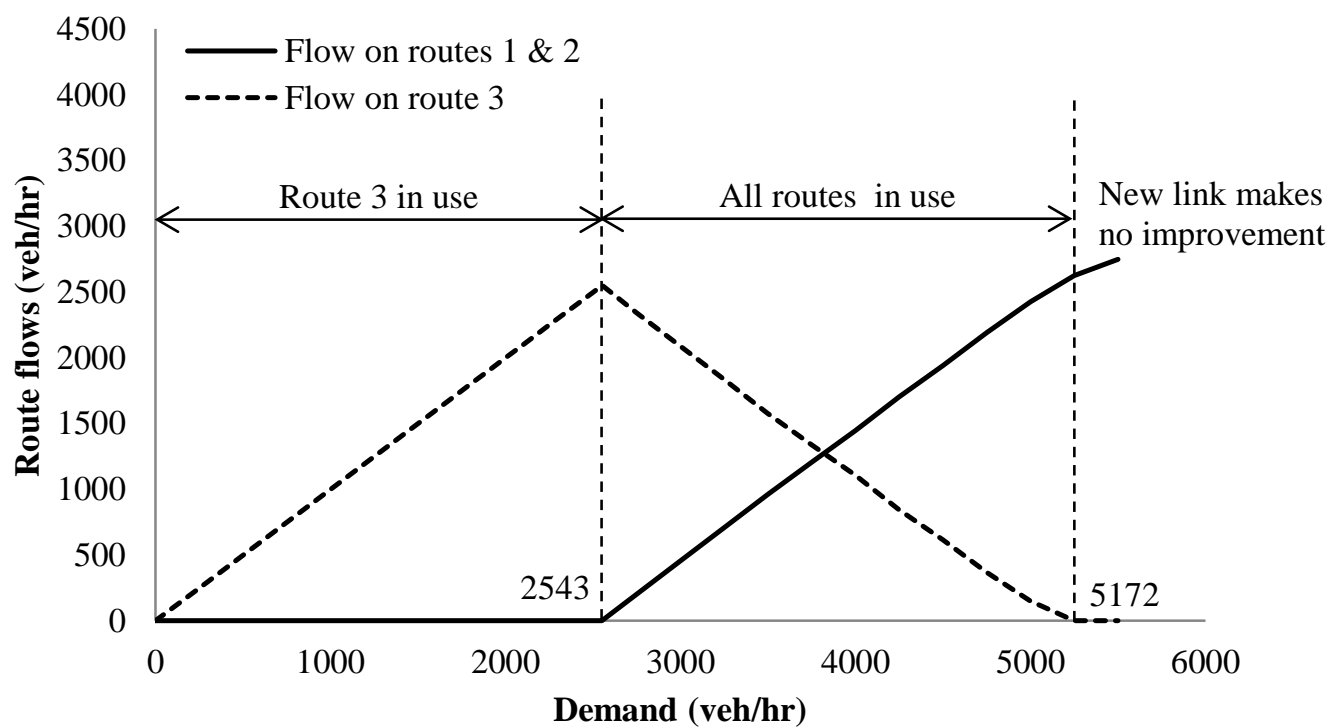

Figure 7 Equilibrium route flows on the 5-link network

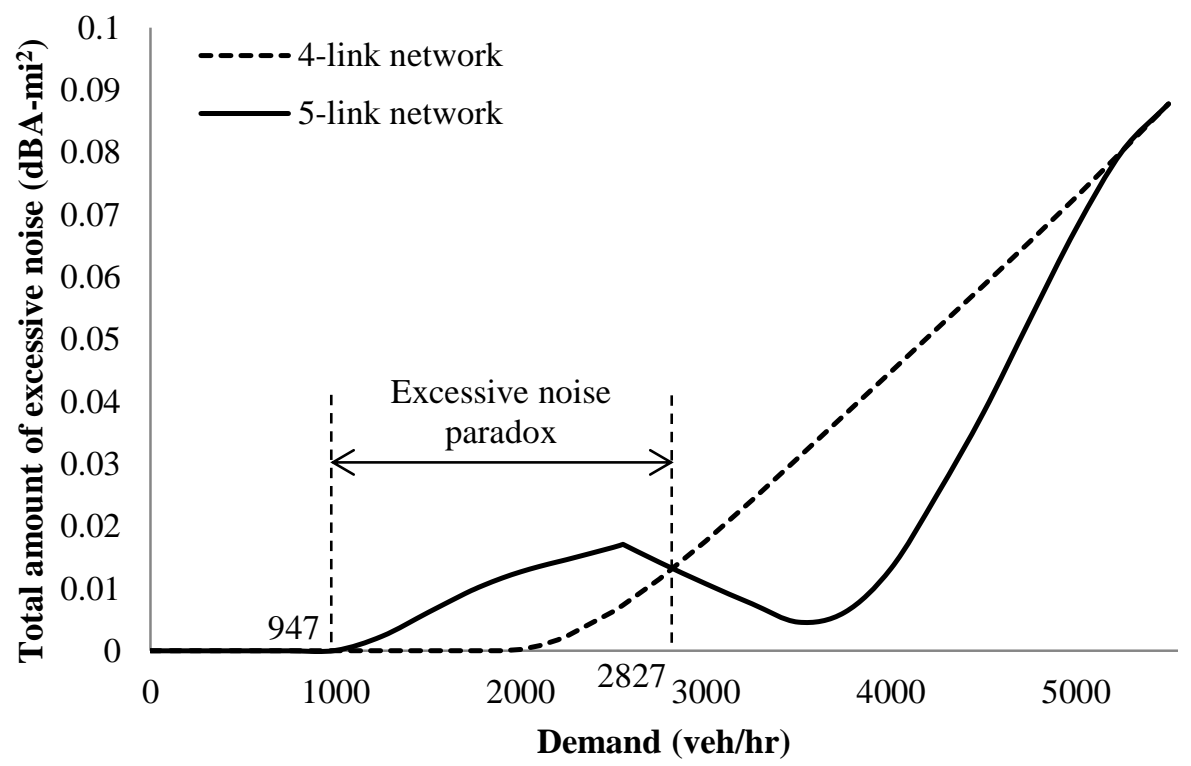

Figure 8 Total amount of excessive noise before/after link $(2,3)$ is added

The amount of total excessive noise is shown in Figure 8. The solid and dashed lines represent the 
total amounts of excessive noise produced by the 5-link and the 4-link networks, respectively. There is one range in which the total excessive noise is larger than that of the 4-link network, which means that after the new link is added, the total amount of excessive noise counterintuitively increases. In other words, the excessive noise paradox occurs. The main reason for such occurrence is that different equilibrium patterns are achieved by the selfish routing behavior of travelers: the new route is the only or main route in use within this demand range in the 5-link network. When only route 3 carries traffic flow (less than the demand of $2543 \mathrm{veh} / \mathrm{hr}$ ), the faster increase of flow on each link of route 3 results in sooner production of excessive noise, while the link flows in the 4-link network is insufficient to cause any excessive noise or only sufficient to cause small excessive noise, leading to the occurrence of excessive noise paradox. When routes 1 and 2 carry traffic flow in the 5-link network in the early stage (i.e., when the demand is slightly large than $2543 \mathrm{veh} / \mathrm{hr}$ ), the total amount of excessive noise produced decreases but remains larger than that of the 4-link network, which is shown as the drop in Figure 8 within the range for the occurrence of this paradox.

\subsection{Simultaneous occurrences of excessive noise and Braess' paradoxes, as well as emissions and Braess' paradoxes}

In this section, the simultaneous occurrences among the $\mathrm{CO}$ and $\mathrm{HC}$ emission paradoxes, Braess' paradox, and excessive noise paradox are investigated. The network setting in Section 3.3 is used. The ranges of demand for their occurrences are shown in Figure 9, Figure 10, and Figure 11, respectively. Comparing them with Figure 8, it can be noticed that the demand range for the occurrence of the Braess paradox overlaps both the ranges for the occurrences of excessive noise paradox and emission paradoxes. The simultaneous occurrences of Braess' paradox and the excessive noise paradox, as well as Braess' paradox and the emission paradox are demonstrated. However, when the demand is low, only the excessive noise paradox occurs and the other two paradoxes do not. This result implies that a network design that considers only total emissions and total system travel cost cannot avoid the occurrence of an excessive noise paradox.

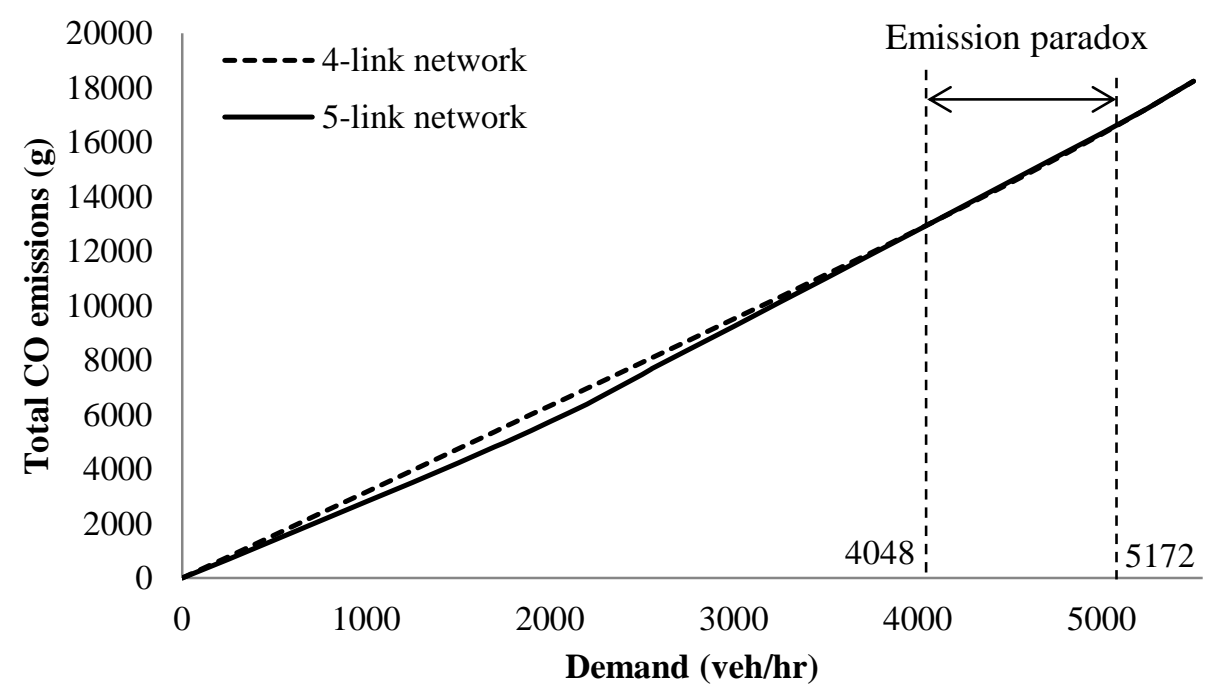




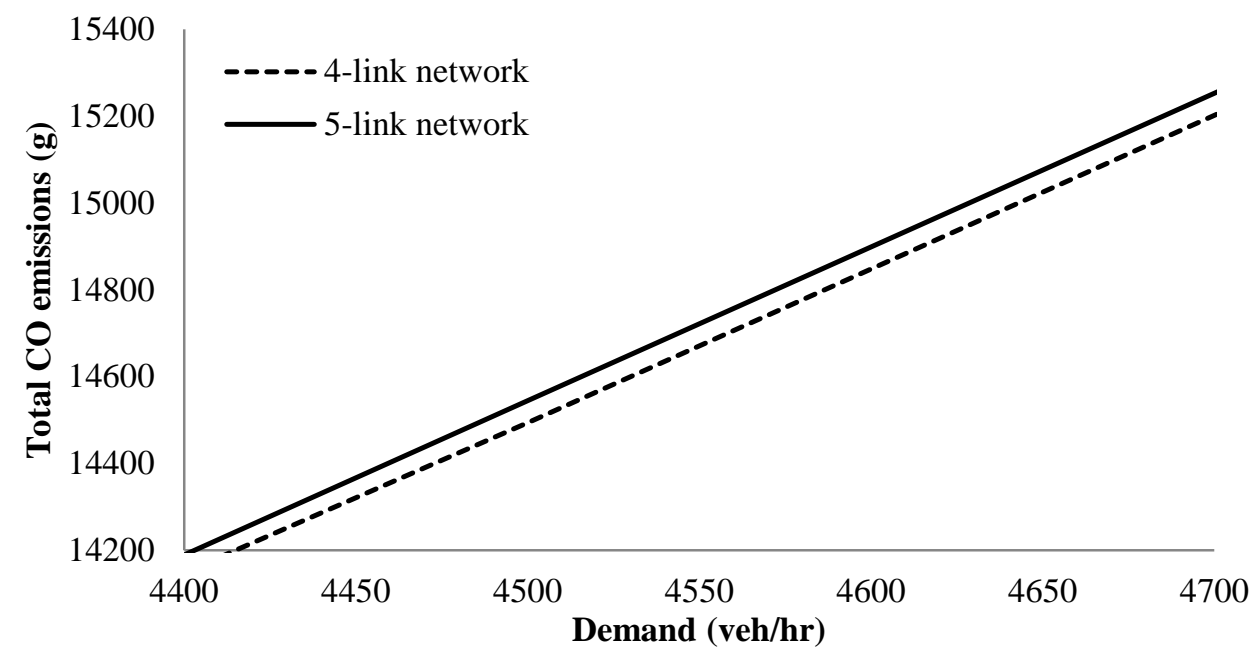

Figure 9 Total $\mathrm{CO}$ emissions before and after link $(2,3)$ is added and an enlarged view within the emission paradox occurrence range
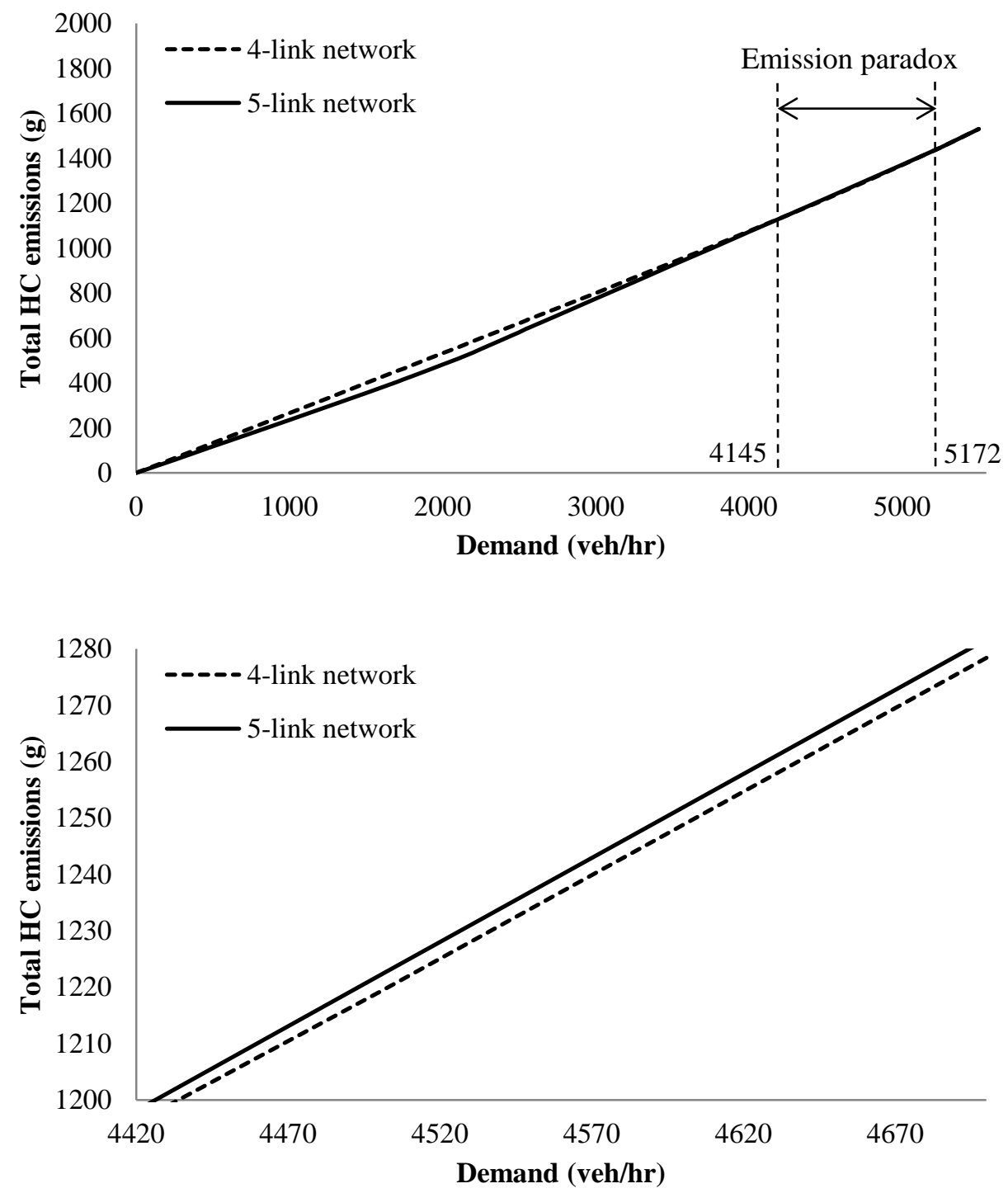

Figure 10 The total HC emissions before and after link $(2,3)$ is added and an enlarged view within the emission paradox occurrence range 


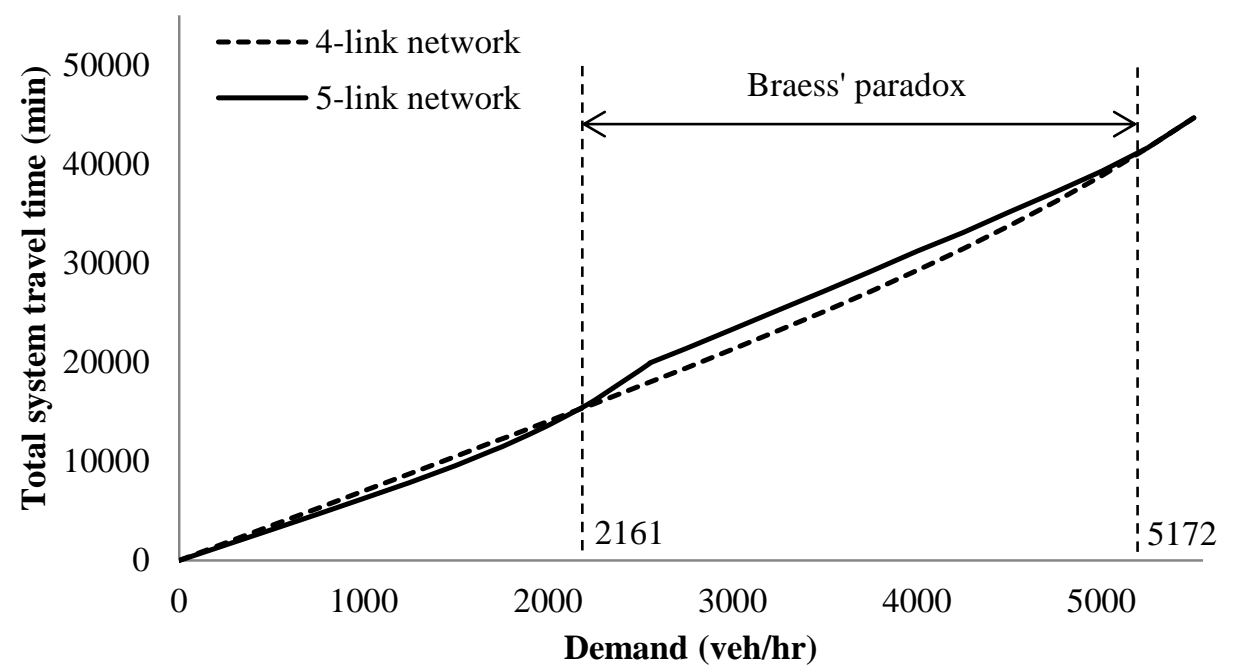

Figure 11 The total system travel times before and after link $(2,3)$ is added

Another observation is that the range of demand for the occurrence of Braess' paradox, as shown in Figure 11, is consistent with the view presented by Pas and Principio (1997), who pointed out that Braess' paradox will not occur when the demand for travel is either too high or too low. However, a similar conclusion cannot be drawn concerning the effect of demand on the excessive noise paradox when a link addition is considered. As shown in Figure 8, the excessive noise paradox occurs with relatively low demand.

\section{SENSITIVITY ANALYSES ON OCCURRENCE OF THE EXCESSIVE NOISE PARADOX}

Pas and Principio (1997) showed that the occurrence of Braess' paradox depends on the link performance function parameters and the demand for travel. In Szeto et al. (2008), similar conclusions were drawn for the occurrence of the emission paradox. In this section, four sensitivity analyses are conducted on factors influencing the occurrence of the excessive noise paradox. First, the influence of demand for travel is investigated, followed by the calibration parameters for the BPR link performance functions, including the coefficient $\beta$ and power $n$. Then, practical link capacity is examined. Finally, free flow travel time, another link attribute to the link performance functions, is also worth investigating. In this study, we convert the free flow travel time into the speed limit, which affects the free flow travel speed directly. The conclusion regarding speed limits is of higher application value and provides better insights for network design problems.

\subsection{Sensitivity analysis of demand for travel}

We study the influence of demand on the occurrence of the excessive noise paradox, again using the example network for Paradox 1 (Figure 4) with the same fixed $D_{1,3}$. Figure 12 provides a clearer picture of how the total amount of excessive noise changes under variations in $D_{1,2}$. 


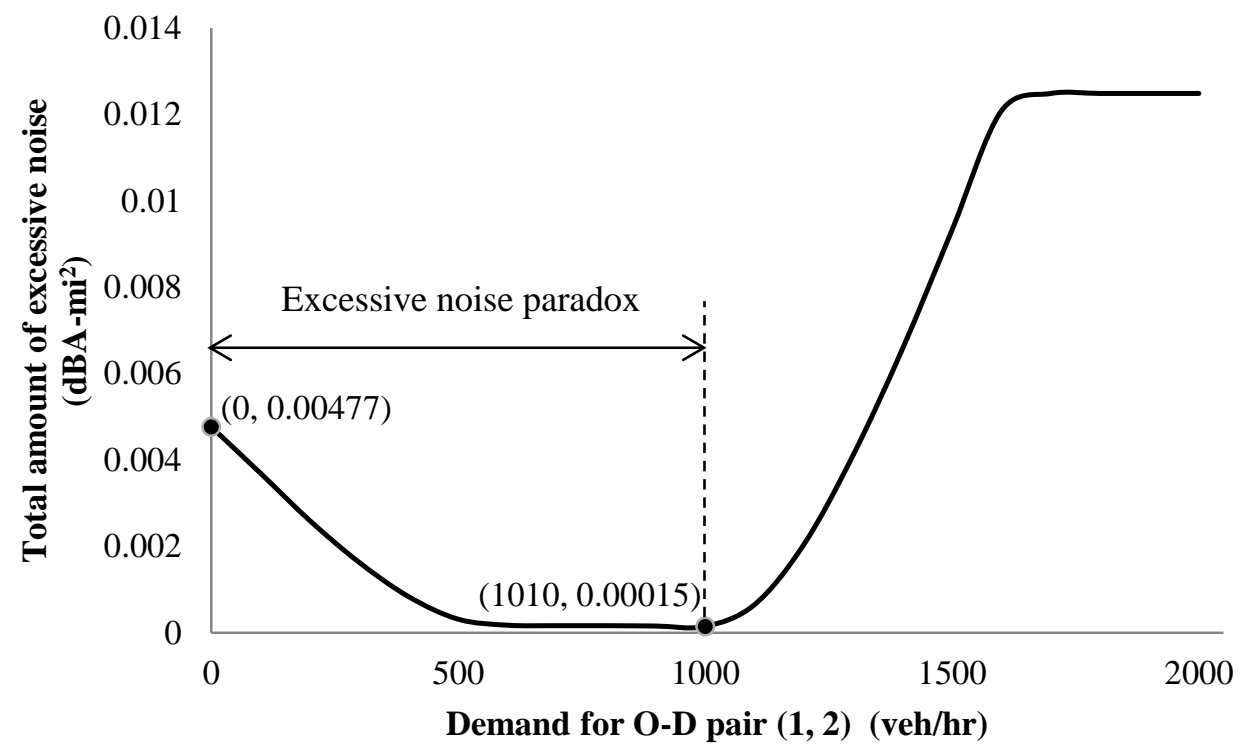

Figure 12 Sensitivity analysis on the effect of demand

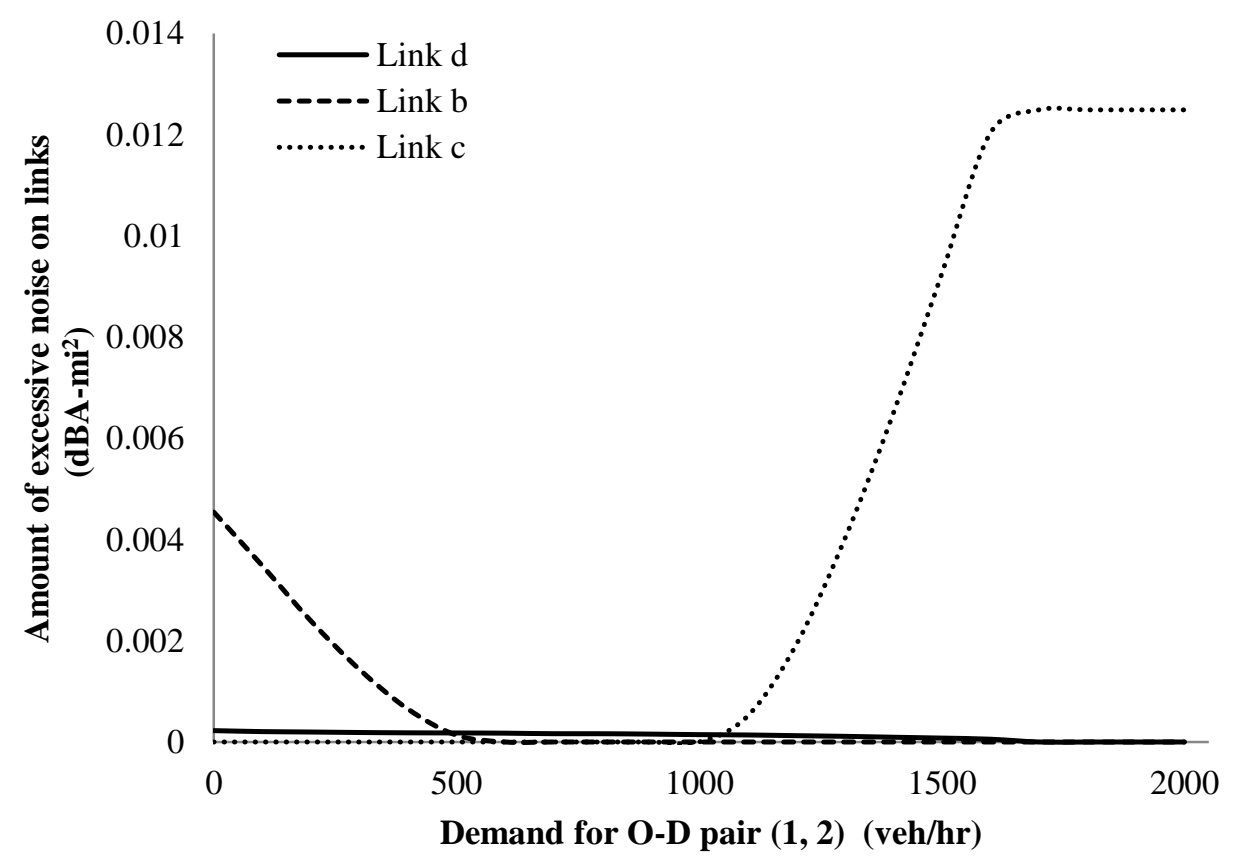

Figure 13 Changes in the link's excessive noise with demand 


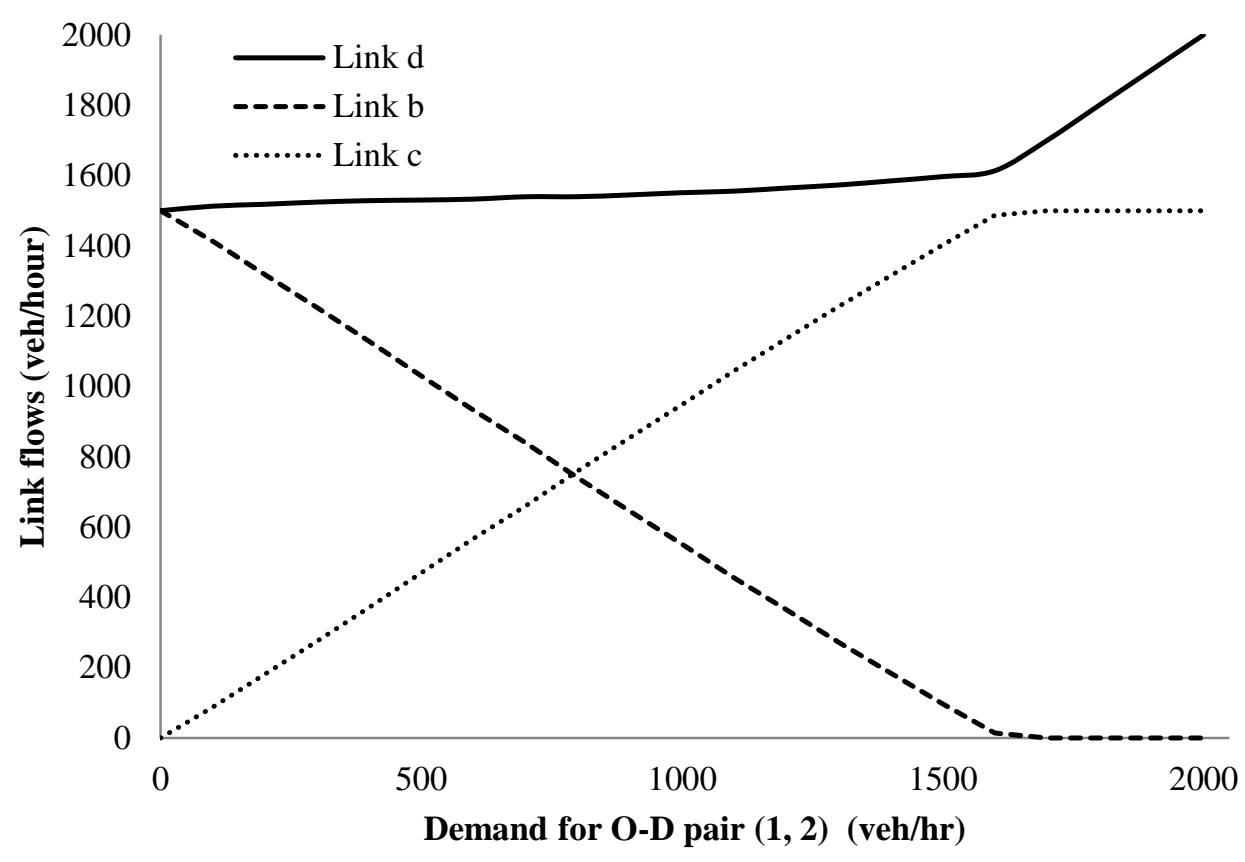

Figure 14 Changes in the link flows

Figure 12 shows that as $D_{1,2}$ increases, the total amount of excessive noise decreases at first, and increases rapidly sharply and reaches a smooth-out. The decreasing portion represents the occurrence of the excessive noise paradox. The excessive noise paradox due to the change in demand can be interpreted in one of two ways. Either the total amount of excessive noise decreases when the demand for travel increases, or the total amount of excessive noise increases with a decrease in the demand for travel.

The paradox was illustrated as Paradox 1 and is explained in Section 3. This paradox occurs when $D_{1,2}$ is relatively low. At this early stage, the excessive noise produced by $c$ equals zero, because of relatively low link flow, which leads to low equivalent noise levels and no excessive noise damage on the link. In the meantime, the excessive noise produced by $d$ is nearly negligible, since the link flow is close to the actual capacity leading to low travel speed. Hence, the excessive noise cost is mainly attributable to link $b$, as can be seen in Figure 13. Moreover, as $D_{1,2}$ changes, the link flow on link $b$ always changes in the reverse direction to reach a new equilibrium flow pattern. As a result, when $D_{1,2}$ increases, the traffic flow on link $b$ decreases, and hence the amount of excessive traffic noise generated on link $b$ decreases. Therefore, the total damage cost of excessive noise falls, and the paradox occurs.

\subsection{Sensitivity analysis of link performance function parameters}

The link performance function represents the relationship between traffic flow and average travel time for any given link in the road network. Linear link cost functions are usually used to simplify the analysis and to provide an analytical solution for the equilibrium condition (e.g., Fisk, 1979; Nagurney, 2000a; and Szeto et al., 2008). Szeto et al. (2008) concluded that the occurrence of the emission paradox depends on the parameters of the link performance functions. In this section, a widely used link performance function developed by the BPR is adopted, as in the last section.

This function has two calibration parameters, $\beta$ and $n$, whose values are commonly set as 0.15 and 4 , 
respectively. To study their effects on the occurrence of excessive noise paradox, the example for Paradox 1 is selected for illustration purposes. First, the value of $\beta$ is fixed as 0.15 , and four values of power $n$ are tested. Figure 15 shows the results, indicating how the total amounts of excessive noise (with different values of $n$ ) change with demand. As we can see, all curves decrease first as $D_{1,2}$ increases, which suggests that Paradox 1 can always occur under the four tested values of power $n$. In addition, the magnitude of change in the total amount of excessive noise is larger if $n$ is larger.

The influence of the parameter $\beta$ is examined in the same way, and the results are shown in Figure 16. These findings lead to the same qualitative conclusions, namely that the excessive noise paradox always happens under these different values of $\beta$, and only the ranges of demand for the occurrence are influenced. The larger value of $\beta$, the sooner the excessive noise paradox occurs as $D_{1,2}$ increases from zero.

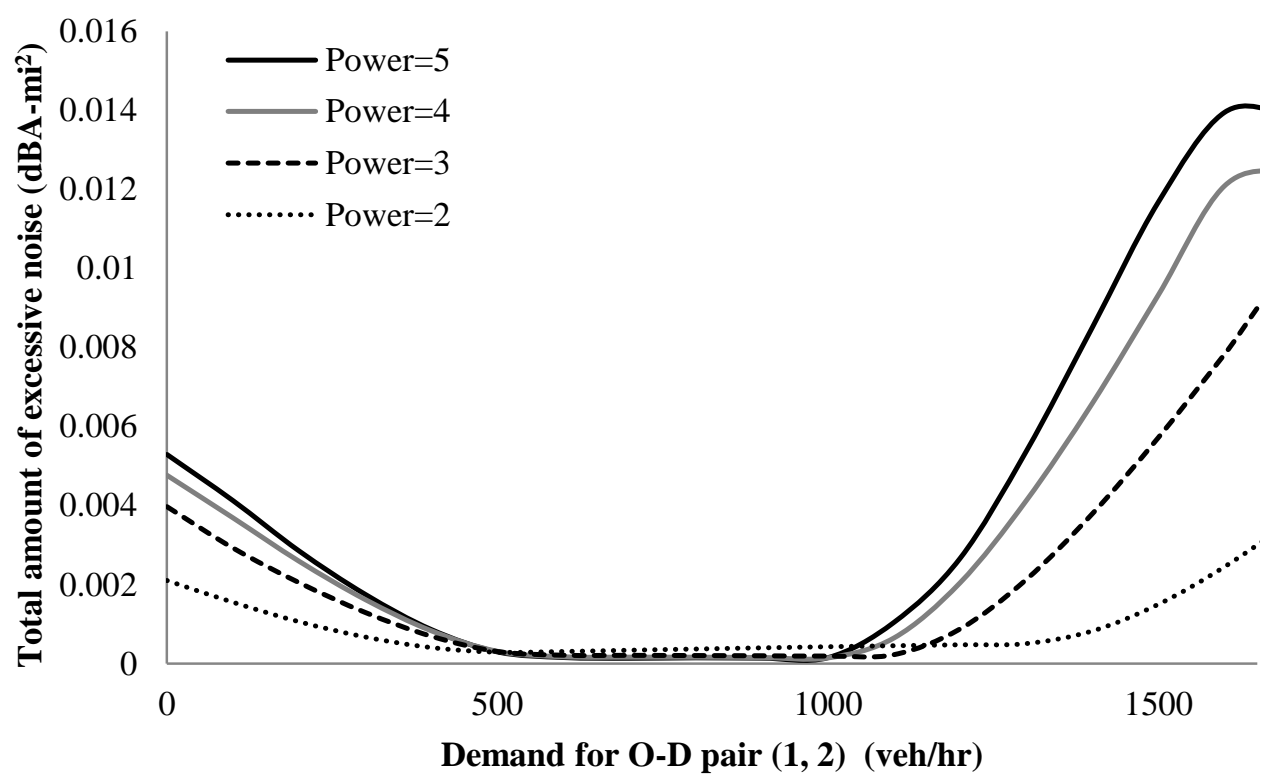

Figure 15 Sensitivity analysis of the power $n$ in the BPR functions 


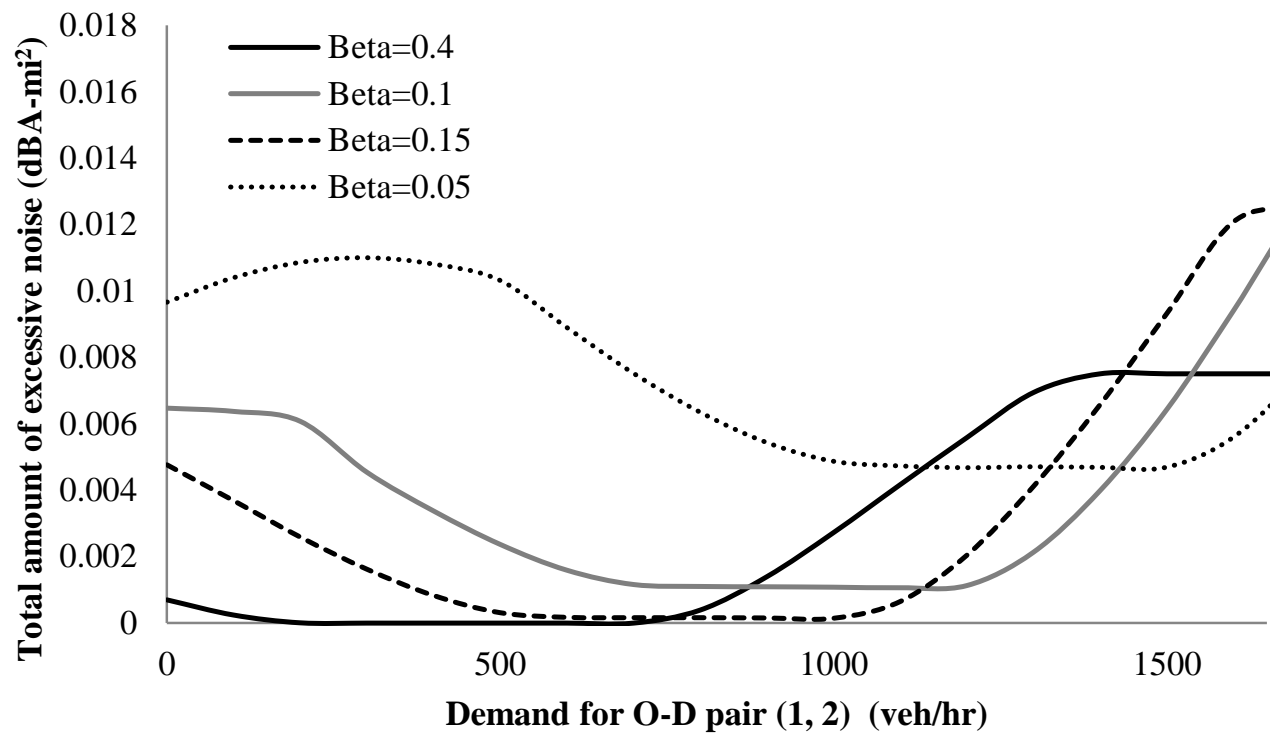

Figure 16 Sensitivity analysis of the parameter $\beta$ in the BPR functions

\subsection{Sensitivity analysis of practical link capacity}

This example demonstrates how the practical link capacity affects the occurrence of the excessive noise paradox. The example for Paradox 1 is considered, but for the practical capacity of link $b$, four tested scenarios are considered. The total amount of excessive noise produced in each scenario is given in Figure 17. According to this figure, we can make three observations. First, the excessive noise paradox occurs among all four tested scenarios. Second, the value of capacity influences the occurrence of the excessive noise paradox, because the value influences the analytical traffic equilibrium solution. Third, we observe that a larger capacity of link $b$ results in more excessive noise produced by the network (and vice versa) when the demand is low. This capacity increment can be considered a variation of Paradox 3, in which adding a new link can be viewed as increasing the capacity from zero to a positive number.

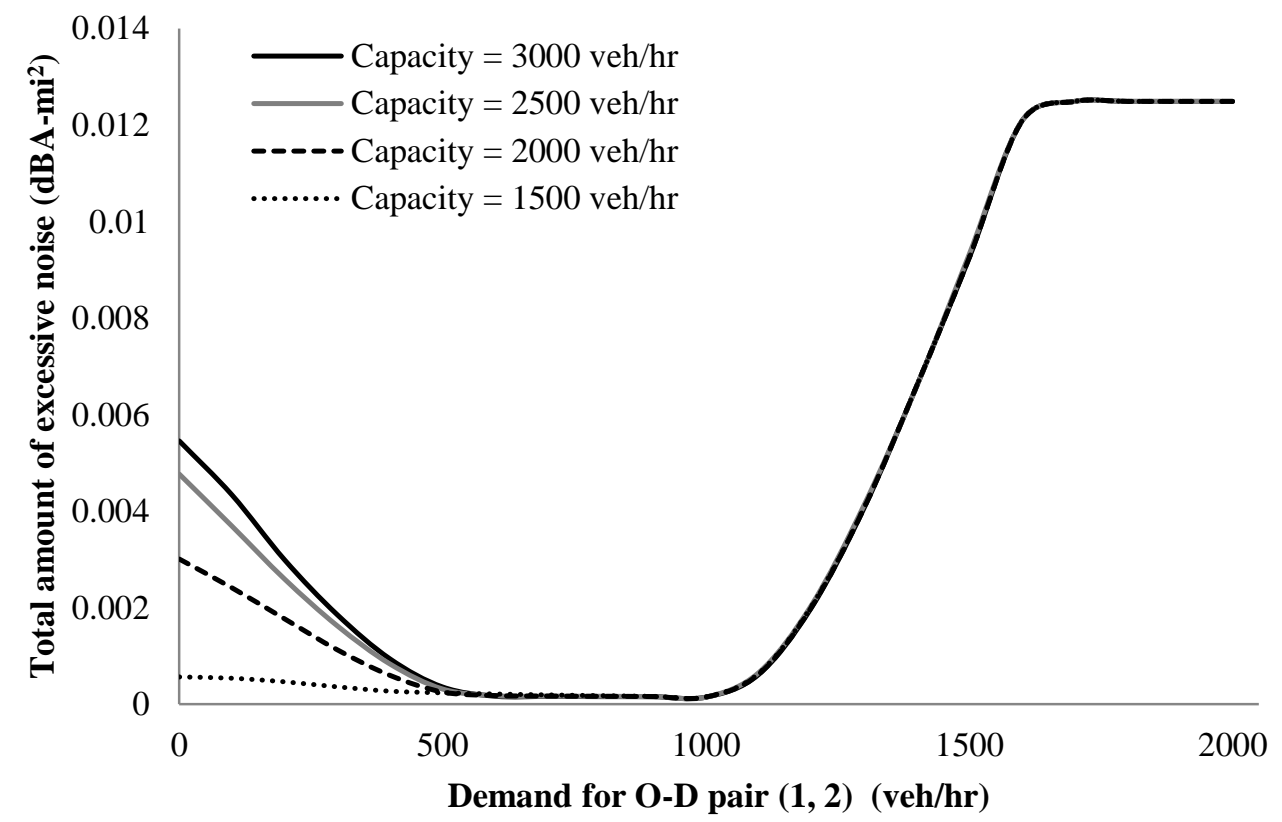

Figure 17 Sensitivity analysis of the practical capacity of link $b$ in the example for Paradox 1 


\subsection{Sensitivity analysis of speed limit}

Paradox 2 in Section 3 has demonstrated that the total amount of excessive noise produced by the network traffic can increase after a speed limit is implemented on a certain link. To investigate the influence of speed limits on the whole network, three speed limit values are tested on the Braess link addition example for Paradox 3. The ranges of demand for the occurrence of the excessive noise paradox (NP), Braess' paradox (BP), and the emission paradoxes (EP) (both CO and HC) due to the addition of the new link under the different speed limits are summarized in Figure 18, Figure 19, and Figure 20.

It can be seen from the comparison that as the free flow travel speed (i.e., the speed limit) decreases, the range of demand for the occurrence of the emission paradoxes increases and the range of demand for the occurrence of the excessive noise paradox shifts to the higher demand direction. Moreover, for a given demand, reducing the speed limit from 70 to 60 (or even 50) $\mathrm{km} / \mathrm{hr}$ leads to the occurrence of the excessive noise paradox (e.g., $2500 \mathrm{veh} / \mathrm{hr}$ ), as well as the emission paradox (e.g., $4500 \mathrm{veh} / \mathrm{hr}$ ). This result shows that implementing a relatively low speed limit scheme may not help to reduce the excessive noise or emissions in this network for a given demand. It also can be observed that the excessive noise and Braess paradox can happen simultaneously with relatively low demand, while the excessive noise and Braess paradox can take place together with high demand.

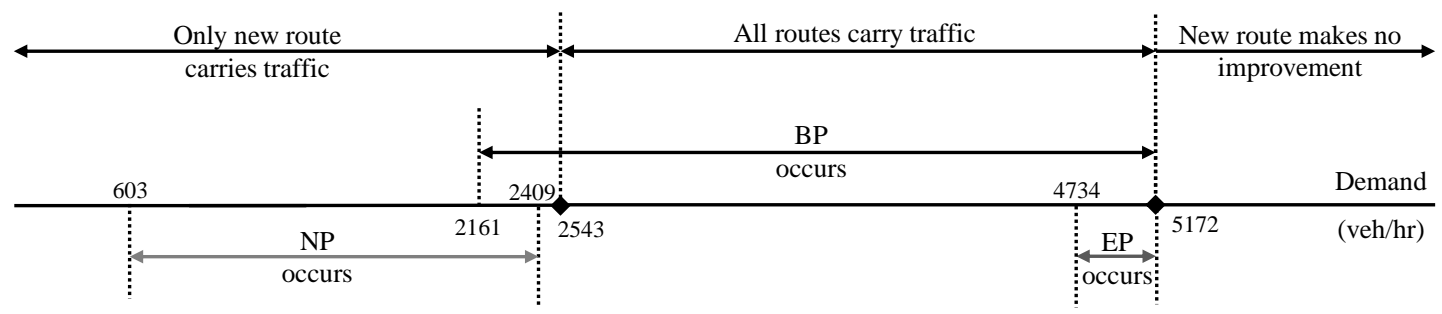

Figure 18 Occurrences of paradoxes (Network speed limit $=70 \mathrm{~km} / \mathrm{hr}$ or $43.50 \mathrm{mph}$ )

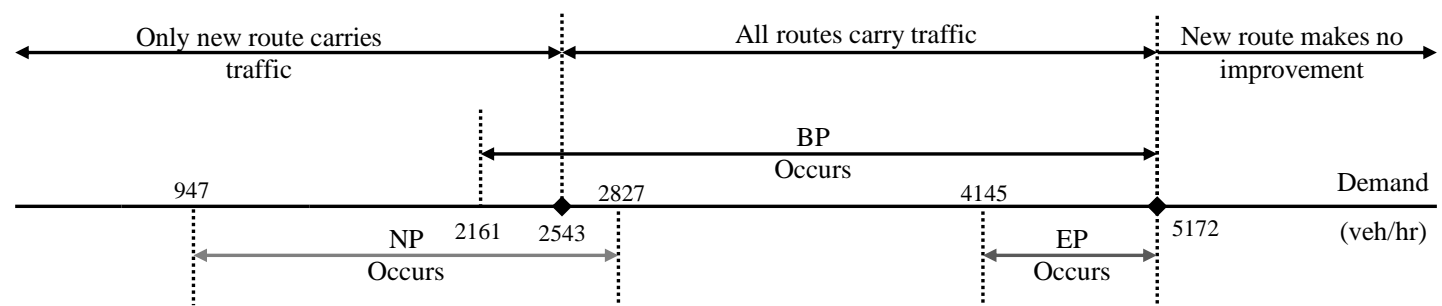

Figure 19 Occurrences of paradoxes (Network speed limit $=60 \mathrm{~km} / \mathrm{hr}$ or $37.28 \mathrm{mph}$ )

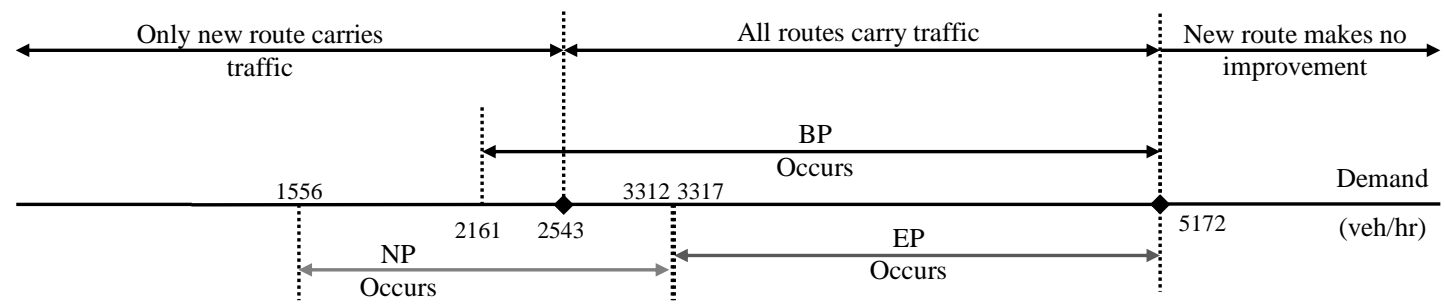

Figure 20 Occurrences of paradoxes (Network speed limit $=50 \mathrm{~km} / \mathrm{hr}$ or $31.07 \mathrm{mph}$ )

\section{CONCLUSIONS}

The existence of an excessive noise paradox is demonstrated in this study through tests involving several hypothetical small networks. Although these networks have simple structures, large networks 
commonly include variations of similar structures. Moreover, we have also illustrated the existence of paradoxes by using the Sioux Falls network. We summarize the key findings as follows.

(a) Our results indicate that some traffic control strategies, or so-called network improvements, may not always improve the transportation system in terms of the excessive noise and emissions produced.

(b) A decrease in travel demand may result in an increase in total excessive noise (and its cost). The occurrence of an excessive noise paradox depends on the demand for travel, and thus does not always occur.

(c) The implementation of a speed limit on a certain link or on the whole network may result in an increase in total excessive noise (and its cost). A network speed limit scheme with a relatively low value may not help to reduce the excessive noise or the emissions in the network.

(d) With a fixed demand, the addition of a link may result in increases to total excessive noise (and its cost), and system travel time (and its cost). An increase in link capacity may also result in an increase in total excessive noise (and its cost).

(e) Braess' paradox and the excessive noise paradox can occur simultaneously, but do not always occur at the same time. A similar conclusion can be drawn to Braess' paradox and the emission paradox.

(f) Under certain conditions, the excessive noise paradox occurs when Braess' paradox does not, which implies that road network improvements designed solely to alleviate congestion may fail to mitigate the increased external damage cost of excessive noise.

(g) Upon the use of BPR functions, the excessive noise paradox always happens under all tested $\beta$ and $n$ values, but the range of demand for this occurrence is affected.

The paradoxical phenomena explored in this study offer new insights for transportation studies associated with environmental sustainability. Especially the non-simultaneous occurrences of the excessive noise paradox, Braess' paradox and the emission paradox indicate that a transportation network design that only aims to mitigate traffic congestion may result in unwanted environmental deterioration, or vice versa. A more comprehensive approach to sustainable road network design is necessary, i.e., an approach that considers environmental sustainability and congestion simultaneously. Although some research (e.g., Li et al., 2014; Long et al., 2014; Jiang \& Szeto, 2015; Miandoabchi et al., 2015; Szeto et al., 2015) has been performed along this line, further studies should be conducted to develop an effective, accurate, and efficient methodology for sustainable road network design. Extending global optimization techniques (e.g., Liu and Wang, 2015; Riemann et al., 2015; Wang et al. 2015 ; 2016) to solve sustainable road network design problems is one possible direction. Moreover, a future study should be conducted to identify the emission and excessive noise paradoxes in an existing network, with the aim of eliminating these issues. Several other paradoxes mentioned in the introduction are not considered in this study, and need to be examined in the future. Another possible direction for research can involve comparing some of these paradoxes, e.g., the capacity paradox, with each of the three paradoxes considered in this study, to examine the conditions for the simultaneous occurrence of all paradoxes concerned. Finally, this study only adopts a static traffic assignment approach to demonstrate the existence of excessive noise paradox. This approach can well capture the traffic behavior under the uncongested or free flow traffic regime. Hence, our example setting is only limited to uncongested scenarios. To examine the existence of excessive noise paradox and the impact of noise under the congested regime, a dynamic traffic assignment modeling approach (e.g., Long et al., 2015; 2016) with the use of fundamental diagram (e.g., Chow et al., 2015) should be used. This is one of our future studies.

\section{Acknowledgements}

This research was jointly supported by grants (Nos. 201411159063 and 201511159095) from the University Research Committee of the University of Hong Kong, and a grant from National Natural Science Foundation of China (No. 71271183). The authors are grateful to the three reviewers and Prof. W.H.K. Lam for their constructive comments. 


\section{REFERENCES}

Akamatsu, T. (2000). A dynamic traffic equilibrium assignment paradox. Transportation Research Part B: Methodological, 34(6), 515-531.

Arnott, R., De Palma, A., \& Lindsey, R. (1993). Properties of dynamic traffic equilibrium involving bottlenecks, including a paradox and metering. Transportation Science, 27(2), 148-160.

Bagby, D. G. (1980). The effects of traffic flow on residential property values. Journal of the American Planning Association, 46(1), 88-94.

Bar-Gera, H. (2012). Transportation Network Test Problems, http://www.bgu.ac.il/ bargera/tntp/ (Accessed on Sept. 20, 2015).

Bateman, I., Day, B., Lake, I., \& Lovett, A. (2001). The Effect of Road Traffic on Residential Property Values: A Literature Review and Hedonic Pricing Study. Edinburgh: Scottish Executive and The Stationery Office.

Benedek, C. M., \& Rilett, L. R. (1998). Equitable traffic assignment with environmental cost functions. Journal of Transportation Engineering, 124(1), 16-22.

Braess, D. (1968). Über ein Paradoxon aus der Verkehrsplanung. Unternehmensforschung, 12(1), 258-268.

Bureau of the Census (1990a). 1990 Census of Housing; General Housing Characteristics, Urbanized Areas (1990 CH-1-1C). Arlington, VA, USA: U.S. Department of Commerce.

Bureau of the Census (1990b). 1990 Census of Population and Housing; Summary Population and Housing Characteristics, United States (1990 CPH-1-1). Arlington, VA, USA: U.S. Department of Commerce.

Cappiello, A. (2002). Modelling Traffic Flow Emissions (MSc thesis). Cambridge, MA, USA: Massachusetts Institute of Technology.

Chow, A. H. F., Li, S., Szeto, W. Y., \& Wang, D. Z. W. (2015). Modelling urban traffic dynamics based upon the variational formulation of kinematic waves. Transportmetrica B: Transport Dynamics, 3(3), 169-191.

Cohen, J. E., \& Kelly, F. P. (1990). A paradox of congestion in a queuing network. Journal of Applied Probability, 730-734.

Dafermos, S., \& Nagurney, A. (1984). On some traffic equilibrium theory paradoxes. Transportation Research Part B: Methodological, 18(2), 101-110.

Daganzo, C. (1996). Two paradoxes of traffic flow on networks with physical queues. In II Symposium Ingenieria de los Transportes (pp. 55-62). Madrid, USA.

DeCorla-Souza, P., Everett, J., Cosby, J., \& Lim, P. (1994). Trip-based approach to estimate emissions with environmental protection agency's MOBILE model. Transportation Research Record: Journal of the Transportation Research Board, 1444, 118-125.

Delucchi, M. A., \& Hsu, S. L. (1996). The External Damage Cost of Direct Noise from Motor Vehicles (Report No. UCD-ITS-RR-96-3 (4)). Davis, CA, USA: Institution of Transportation Studies, University of California, Davis.

Department of Transport (DOT) (1988). Calculation of Road Traffic Noise. London: HMSO, UK.

Downs, A. (1962). The law of peak-hour expressway congestion. Traffic Quarterly, 16(3), 393-409.

FHWA, U. (1997). Federal Highway Cost Allocation Study. USDOT (www.dot.gov), at http://www.fhwa.dot.gov/policy/hcas/summary/sum5.cfm\#other.

Fisk, C. (1979). More paradoxes in the equilibrium assignment problem. Transportation Research Part B: Methodological, 13(4), 305-309.

Forkenbrock, D. J. (1999). External costs of intercity truck freight transportation. Transportation Research Part A: Policy and Practice, 33(7), 505-526.

Fuller, J. W., Hokanson, J. B., Haugaard, J., \& Stoner, J. (1983). Measurements of Highway User Interference Costs and Air Pollution and Noise Damage Costs Issue 34 of Final Report. Iowa, USA: Institute of Urban and Regional Research, Oakdale Campus, University of Iowa.

Haling, D., \& Cohen, H. (1996). Residential noise damage costs caused by motor vehicles. Transportation Research Record: Journal of the Transportation Research Board, 1559, 84-93. 
Jackson, W. E., Wohlers, H. C., \& DeCoursey, W. (1969). Determining the costs of air pollution control. Journal of the Air Pollution Control Association, 19(12), 917-923.

Jiang, Y., \& Szeto, W. Y. (2015). Time-dependent transportation network design that considers health cost. Transportmetrica A: Transport Science, 11(1), 74-101.

Knight, F. H. (1924). Some fallacies in the interpretation of social cost. Quarterly Journal of Economics, 38, 582-606.

Khisty, C.J. Transportation Engineering: An Introduction (3rd edition). Prentice Hall Inc. 2003.

Levinson, D., Gillen, D., Kanafani, A., \& Mathieu, J. M. (1996). The Full Cost of Intercity Transportation -A Comparison of High Speed Rail, Air and Highway Transportation in California. (Report No. UCB-ITS-RR-96-3). Berkeley, CA, USA: Institute of Transportation Studies, University of California.

Li, Z.-C., Lam, W. H. K., Wong, S. C., \& Sumalee, A. (2012). Environmentally sustainable toll design for congested road networks with uncertain demand. International Journal of Sustainable Transportation, 6(3), 127-155.

Li, Z.-C., Li, Z.-K., \& Lam, W. H. K. (2014). An integrated design of sustainable land use and transportation system with uncertainty in future population. Transportmetrica A: Transport Science, 10(2), 160-185.

Lin, W.-H., \& Lo, H. K. (2009). Investigating Braess' paradox with time-dependent queues. Transportation Science, 43(1), 117-126.

Liu, H. X., \& Wang, D. Z. W. (2015). Global optimization method for network design problem with stochastic user equilibrium. Transportation Research Part B: Methodological, 72, 20-39.

Long, J. C., Szeto, W. Y., \& Huang, H. J. (2014). A bi-objective turning restriction design problem in urban road networks. European Journal of Operational Research, 237(2), 426-439.

Long, J. C., Szeto, W. Y., Shi, Q., Gao, Z. Y., \& Huang, H.-J. (2015). A nonlinear equation system approach to the dynamic stochastic user equilibrium simultaneous route and departure time choice problem. Transportmetrica A: Transport Science, 11(5), 388-419.

Long, J. C., Szeto, W. Y., Gao, Z. Y., Huang, H. J., \& Shi, Q. (2016). The nonlinear equation system approach to solving dynamic user optimal simultaneous route and departure time choice problems. Transportation Research Part B, 83, 179-206.

Maibach, M., Schreyer, C., Sutter, D., van Essen, H. P., Boon, B. H., Smokers, R., \& Bak, M. (2008). Handbook on Estimation of External Costs in the Transport Sector. Delft: CE Delft.

Matthews, H. S. (1999). The External Costs of Air Pollution and the Environmental Impact of the Consumer in the U. S. Economy (PhD thesis). Pittsburg, USA: Carnegie Mellon University.

Mayeres, I., Ochelen, S., \& Proost, S. (1996). The marginal external costs of urban transport. Transportation Research Part D: Transport and Environment, 1(2), 111-130.

Miandoabchi, E., Daneshzand, F., Farahani, R. Z., \& Szeto, W. Y. (2015). Time-dependent discrete road network design with both tactical and strategic decisions. Journal of the Operational Research Society, 66, 894-913.

Modra, J. D., \& Bennett, D. W. (1985). Cost-benefit analysis of the application of traffic noise insulation measures to existing houses. Publication of the Australian Road Research Board.

Nagurney, A. (2000a). Congested urban transportation networks and emission paradoxes. Transportation Research Part D: Transport and Environment, 5(2), 145-151.

Nagurney, A. (2000b). Sustainable Transportation Networks. Cheltenham: Edward Elgar Publishers.

Nagurney, A., Qiang, Q., \& Nagurney, L. S. (2010). Environmental impact assessment of transportation networks with degradable links in an era of climate change. International Journal of Sustainable Transportation, 4(3), 154-171.

Nelson, J. P. (1982). Highway noise and property values: A survey of recent evidence. Journal of Transport Economics and Policy, 16(2), 117-138.

Nie, Y. M., \& Li, Q. (2013). An eco-routing model considering microscopic vehicle operating conditions. Transportation Research Part B: Methodological, 55, 154-170.

Oneyama, H., Oguchi, T., \& Kuwahara, M. (2001). Estimation model of vehicle emission considering variation of running speed. Journal of the Eastern Asia Society for Transportation Studies, 4(5), 105-117.

Pas, E. I., \& Principio, S. L. (1997). Braess' paradox: Some new insights. Transportation Research Part B: Methodological, 31(3), 265-276. 
Passchier-Vermeer, W., \& Passchier W. F. (2000). Noise exposure and public health. Environmental Health Perspectives, 108, 123-131.

Patil, G. R., Aultman-Hall, L., \& Holmén, B. A. (2009). Environmental traffic assignment: Developing emission-based models. Presented at the Transportation Research Board 88th Annual Meeting.

Penic, M. A., \& Upchurch, J. (1992). TRANSYT-7F: Enhancement for fuel consumption, pollution emissions, and user costs. Transportation Research Record: Journal of the Transportation Research Board, 1360, 104-111.

Pigou, A. C. (1920). The Economics of Welfare. London: Macmillan.

Quartieri, J., Mastorakis, N. E., Iannone, G., Guarnaccia, C., D’Ambrosio, S., Troisi, A., \& Lenza, T. L. L. (2009). A review of traffic noise predictive models. In Proceedings of the 5th World Scientific and Engineering Academy and Society International Conference on "Applied and Theoretical Mechanics" (MECHANICS'09) (pp. 72-80). Puerto De La Cruz, Canary Islands, Spain.

Riemann R, Wang D. Z. W., \& Busch F. (2015). Optimal location of wireless charging facilities for electric vehicles: Flow-capturing location model with stochastic user equilibrium. Transportation Research Part C, 58 (part A), 1-12.

RLS (1990). Richtlinien für den Lärmschutz an Strassen, Bonn, Germany: Der Bundesminister für Verkehr (in German).

Roughgarden, T. (2005). Selfish Routing and the Price of Anarchy. Cambridge: MIT press.

Sharma, S., \& Mathew, T. V. (2007). Transportation network design considering emissions as bilevel optimization problem. In Transportation Research Board 86th Annual Meeting Compendium of Papers CD-ROM Washington, D. C.: Transportation Research Board.

Sheffi, Y., \& Daganzo, C. (1978). Another paradox of traffic flow. Transportation Research, 12(1), 43-46.

Smit, R., Brown, A. L., \& Chan, Y. C. (2008). Do air pollution emissions and fuel consumption models for roadways include the effects of congestion in the roadway traffic flow? Environmental Modelling \& Software, 23(10), 1262-1270.

Smith, M. J. (1978). In a road network, increasing delay locally can reduce delay globally. Transportation Research, 12(6), 419-422.

Soltau, J. P., \& Campbell, K. (1968). Paper 9: The Sampling and Measurement of Exhaust Emissions from Motor Vehicles. Proceedings of the Institution of Mechanical Engineers, Conference Proceedings, 183(5), 81-94.

Steele, C. (2001). A critical review of some traffic noise prediction models. Applied Acoustics, 62(3), 271-287.

Steinberg, R., \& Stone, R. E. (1988). The prevalence of paradoxes in transportation equilibrium problems. Transportation Science, 22(4), 231-241.

Szeto, W. Y., \& Jiang, Y. (2014). Transit assignment: Approach-based formulation, extragradient method, and paradox. Transportation Research Part B: Methodological, 62, 51-76.

Szeto, W. Y., Jaber, X. Q., \& Wong, S. C. (2012). Road network equilibrium approaches to environmental sustainability. Transport Reviews: A Transnational Transdisciplinary Journal, 32(4), 491-518.

Szeto, W. Y., Jiang, Y., Wang, D. Z. W., \& Sumalee, A. (2015). A sustainable road network design problem with land use transportation interaction over time. Networks and Spatial Economics, 15(3), 791-822.

Szeto, W. Y., Li, X., \& O’Mahony, M. (2008). Simultaneous occurrence of Braess' and emission paradoxes. In Proceedings of the 6th International Conference on Traffic and Transportation Studies, 625-634.

Szeto, W. Y., O’Brien, L., \& O'Mahony, M. (2009). Measuring network reliability by considering paradoxes. Transportation Research Record: Journal of the Transportation Research Board, 2090, 42-50.

Szeto, W. Y., Wang, Y., \& Wong, S. C. (2014). The chemical reaction optimization approach to solving the environmentally sustainable network design problem. Computer-Aided Civil and Infrastructure Engineering, 29(2), 140-158.

Thomson, J. M. (1977). Great Cities and Their Traffic. London: Victor Gollancz. 
Wang, D. Z. W., Liu, H. X., \& Szeto, W. Y. (2015). A novel discrete network design problem formulation and its global optimization solution algorithm. Transportation Research Part E: Logistics and Transportation Review, 79, 213-230.

Wang, D. Z. W., Liu, H., Szeto, W. Y., \& Chow, A. H. F. (2016). Identification of critical combination of vulnerable links in transportation networks - a global optimisation approach. Transportmetrica A: Transport Science, 12(4), 346-365.

Yang, H., \& Bell, M. G. H. (1998). Models and algorithms for road network design: A review and some new developments. Transport Reviews, 18(3), 257-278.

Yao, J., \& Chen, A. (2014). An analysis of logit and weibit route choices in stochastic assignment paradox. Transportation Research Part B: Methodological, 69, 31-49.

Yin, Y., \& Lawphongpanich, S. (2006). Internalizing emission externality on road networks. Transportation Research Part D: Transport and Environment, 11(4), 292-301.

Zhang, X., Lam, W. H. K., \& Huang, H. J. (2008). Braess's paradoxes in dynamic traffic assignment with simultaneous departure time and route choices. Transportmetrica, 4(3), 209-225. 